NBSIR 81-2350

\title{
Smoldering Combustion Hazards of Thermal-Insulation Materials
}

U.S. DEPARTMENT OF COMMERCE

National Bureau of Standards

National Engineering Laboratory

Center for Fire Research

Washington, DC 20234

August 1981

Interim Report

Prepared for:

U.S. Department of Energy Oak Ridge National Laboratory

Oak Ridge, Tennessee 37830 


\section{DISCLAIMER}

This report was prepared as an account of work sponsored by an agency of the United States Government. Neither the United States Government nor any agency Thereof, nor any of their employees, makes any warranty, express or implied, or assumes any legal liability or responsibility for the accuracy, completeness, or usefulness of any information, apparatus, product, or process disclosed, or represents that its use would not infringe privately owned rights. Reference herein to any specific commercial product, process, or service by trade name, trademark, manufacturer, or otherwise does not necessarily constitute or imply its endorsement, recommendation, or favoring by the United States Government or any agency thereof. The views and opinions of authors expressed herein do not necessarily state or reflect those of the United States Government or any agency thereof. 


\section{DISCLAIMER}

Portions of this document may be illegible in electronic image products. Images are produced from the best available original document. 


\section{SMOLDERING COMBUSTION HAZARDS OF THERMAL-INSULATION MATERIALS}

T. J. Ohlemiller

U.S. DEPARTMENT OF COMMERCE National Bureau of Standards National Engineering Laboratory Center for Fire Research Washington, DC 20234

This book was prepared as an account of work sponsored by an pgency of the United States Government. Neither the United States Government nor any agency thereot, nor any of their employees, makes any warnany, express or implied. or assumes any legal hiability or responsibility for the accuracy.

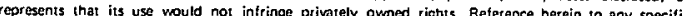

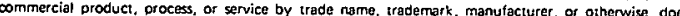
nol necessarily constitute or imply its endorsement, recommendation, or favoring by the United States Government or any agency thereor. The views and apinions of authars expressed herein do no

August 1981

Interim Report

Prepared for:

U.S. Department of Energy

Oak Ridge National Lahnratory

Oak Ridge, Tennessee 37830

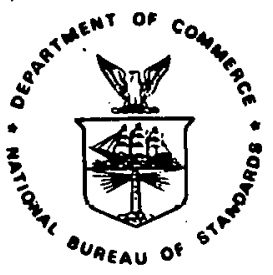

U.S. DEPARTMENT OF COMMERCE, Malcolm Baldrige, Secretary NATIONAL BUREAU Of STANDARDS, Ernest Ambler, Director

DISTRIBUTION OF THS DOCUMENT IS UALIMITED 
THIS PAGE

\section{WAS INTENTIONALLY LEFT BLANK}


Abstract . . . . . . . . . .... . . . . . . . . . . . . . . . . 1

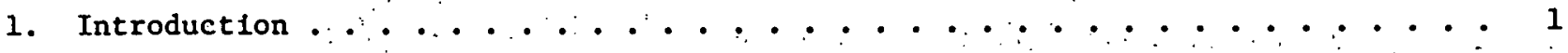

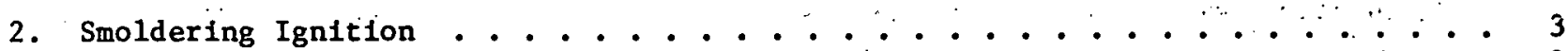

2.1 Nature of the Problem . . . . . . . . . . . . . . . . . . . . 3

2.2 Summary of Ignition Test Studies ........................... . 4

2.3 Recommendations Concerning Smolder Ignftion Test Development . . . . . . . 5

2.4 Follow-on Work on Smolder Ignttion . . . . . . . . . . . . . . . . . . . 7

3. Smolder Propagation . . . . . . . . . . . . . . . . . . . . . . . 7

3.1 Background . . . . . . . .... . . . . ............... . 7

3.2 objectives ............................... 8

3.3 System Studied and Procedures ....................... 8

$3: 4$ Discussion of Typical Results . . . . . . . . . . . . . . . . . . . . 10

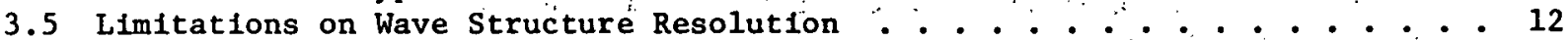

3.6 Factors Controlling Wave Shape . . . . . . . . . . . . . . . 14

3.7 Some Effects of Boric Acid . . . . . . . . . . . . . . . . . . . . . . 17

3.8 Estimate of Heat Release Distribution ...................... . 19

3.9 Summary of Wave Structure Findings . . . . . . . . . . . . . . . . . . 23

4. References . . . . . . . . . . . . . . . . . . . . . . . . 24

Figures . . . . . . . . . . . . . . . . . . . . . . . . . . . . 26-32

Appendix I Cellulosic Insulation Material III. Effects of Heat Flow Geometry on Smolder Initiation .......................... 33 
Figure 1. Attic mock-up adapted for smolder propagation studies . . . . . . . . 26.

Figure 2. Typical profiles from floating thermocouples at different depths in the insulation bed ... . . . . . . . . . . . . . . . . . . 27

Figure 3. Cross-sectional snapshot of steady-state smolder wave structure in nominally unretarded insulation . . . . . . . . . . . . . . . . . . . 28

Figure 4. Cross-sectional snapshot of steady-state smolder propagation in insulation with $25 \%$ boric acid add-on . . . . . . . . . . . . . . . . . . . . . 29

Figure 5. Sketch of oxygen inflow paths and heat release zones in spreading smolder wavc, infcrred from analyaio of wave atxucturc profilco . . . . . . . . 30

Figure 6. Thermal analytical results for unretarded and borlc acid-retarded inoulation . . . . . . . . . . . . . . . ... . . . ... . 31

Figure 7. Heat effects (endothermic and exothermic) inferred from temperature-time trace provided by shallow floating thermocouples . . . . . . . . . . . . 32

\section{I.TST OF TABT.ES}

Table I. Lateral smolder propagation rates through $18 \mathrm{~cm}$ deep cellulosic insulation layers . . . . . . . . . . . . . . . . . . . . . . 10

Table II. Summary of integrated heat effects along $1 \rightarrow D$ particle path through smolder wave . . . . . . . . . . . . . . . . . . . . . . 21 


\section{Smoldering Combustion Hazards of Thermal Insulation Materials}

Thomas J. Ohlemiller.

National Bureau of Standards
Washington, D.C. 20234

The smoldering combustion hazards of cellulosic loose fill insulation materials fall into three categories: smolder initiation, smolder propagation, and transition from smoldering into flaming. Previous findings on the initiation problem are summarized briefly. They serve as the basis for recommendations on an improved smolder ignition test method which is designed to give ignition temperatures comparable to those in practice. The proposed test method requires checking against full-scale mock-up results before it can be considered for implementation.

Smolder propagation, driven by buoyant convection, through a thick $(18 \mathrm{~cm})$ layer of cellulosic insulation has been extensively examined. A heavy (25\% addon) loading of boric acid (a widely used smolder retardant) cuts the propagation rate in half (from approx. 0.3 to $0.15 \mathrm{~cm} / \mathrm{min}$ ) but does not come close to stopping this process. Analysis of experimental profiles for temperature, oxygen level, and remaining organic fraction strongly indicates that the smolder wave is oxygen-supply controlled and that it involves both first and second stages of oxidative heat release from the insulation material. The balance of involvement of the two stages varies with depth in the layer. It appears that efforts to develop improved means of suppressing smolder propagation must be directed at the entire oxidation process. However, since borlc acid is fairly effective at slowing the second stage of oxidation, most new efforts should be almed at the first stage of oxidation (which also is responsible for smolder inftiation).

Smolder transition to flaming is the next problem to be studied; the above results form the reference state that is perturbed into flaming when air is forced to flow through or around the smoldering insulation.

\section{Introduction}

The work reported here is a continuation of that described in ORNL/Sub 7686/1 (ref. 1). The work began at Princeton University and is continuing at the National Bureau of Standards Center for Fire Research. 
The focus of this work to date has been the smoldering combustion hazards of thermal insulation materials, in particular, loose-fill cellulosic insulation. This type of insulation is a re-cycled paper product, typically made from newsprint which is mainly ground wood. The normal combustibility of wood is accentuated when it is ground to a fibrous form and utilized in low bulk density layers. The flaming aspects of this combustibility are relatively well-controlled by presently available additives such as borax. Smoldering combustibility is less well-controlled by present additives (e.g., boric actd). As a result, smoldering may be initiated in state-of-the-art insulations that are improperly installed in contact with heat sources such as recessed light fixtures.

It should be noted that flaming and smoldering are fundamentally different kinds of combustion so it is to be expected that they would respond differently to retardants. Smoldering is not a well-characterized combustion process since it involves complex snlid phase oxidation chemistry coupled to mass and energy transport processes. One of the goals of the present study is to shed as much light as possible on the nature of smoldering phenomena in cellulosic insulations so that this form of combustion can be suppressed.

There are three aspects of smoldering combustibility that are pertinent to the insulation usage hazard. First is the ignitability to smoldering. There are several questions about this aspect that one can ask. These concern the conditions that lead to smolder initiation, the factors that influence this process, the feasibility of realistically measuring the smolder ignitability tendency of an insulation, and the changes necessary to lessen this tendency. Most of these questions have been addressed in the current work; the status of the answers is discussed below.

The second aspect of smolder combustibility concerns the propagation process that occurs subsequent to ignition. The smolder reaction zone may spread outward from the ignition source indefinitely as long as there is a continuous layer of insulation. One could ask the same questions as above about this process. It is currently under study and it. is apparent that the answers are substantially more complex than in the ignition situation. The results to date are summarized below.

The third aspect of smolder combustibility is that of the transition from smoldering to flaming combustion; this occurs, typically, if the smolder zone receives a sharply increased air supply. Again the same questions apply. This subject has not yet been examined but will be briefly scanned in the coming year. It is important because it is the mechanism whereby the smoldering process leads to rapid development of threats to life safety and property destruction.

In section 2 we briefly summarize the smolder ignition work. This work has been the subject of three papers. The first two were included as appendices in last year's report (ref. 1); they have been published in Combustion Science and Technology (ref. 2, 3). The 
third paper is included here as Appendix I; it has been accepted for publication in the same journal. Recommendations for a revised ignition test method are discussed here in some detail. The next area of the smolder ignition problem in need of study is also indicated.

The results to date on the process of smolder propagation are discussed in some detail here (Section 3) since they have not been previously reported. Finally we conclude with a brief discussion of what problem areas need further study.

\section{Smoldering Ignition}

\subsection{Nature of the Problem}

The initiation of smoldering in cellulosic loose-fill insulations appears to be most probably and most frequently a hazard when the insulation is in contact with large area heat sources such as recessed light fixtures $(1,4,5,6,7)$. A light fixture is essentially a constant power heat source; the temperatures achieved within it at steady state depend on the rate of heat loss. When insulation is placed around the body of a fixture recessed above the celling level, much of the pathway for heat loss is severely inhibited. If an oversize lightbulb is then used, the steady state surface temperature of the fixture may reach into the range from about $225-275^{\circ} \mathrm{C}$ where current insulations begin to react appreciably with oxygen $(1,6)$. These reactions are exothermic so that they can become self-accelerating. If the initiating source, 1.e. the light fixture, is at or above a minimum critical temperature, a self-sustaining reaction process begins in the insulation. It can spread away from the light fixture because the reactions themselves now produce enough heat to ignite adjacent elements of the insulation.

The reactions that produce this heat are not in the gas phase but rather involve a direct attack of oxygen on the wood fibers that comprise the insulation. These heterogeneous reactions produce the unique characteristics of smoldering; their nature 1s not well defined at present.

The minimum critical temperature for ignition of smoldering is not a unique property of the insulation. Ignition occurs when the local rate of heat release continues to exceed the rate of heat loss. Heat losses depend on the geometry of the heat source, the thickness of the insulation, its thermal conductivity, etc. These factors, in addition to the reactivity and exothermicity of the insulation, must enter into the determination of the critical conditions that dictate the smolder ignition borderline. This complicates the design of a test method that will provide a unique and meaningful measure of the tendency of an insulation to ignite to smolder. 


\subsection{Summary of Ignition Test Studies}

The total problem of a constant power, extended area heat source imbedded in a layer of oxidizable insulation has never been treated analytically. Although this could be done in principle, it would get quite involved and overly specialized if all of the realistic details were incorporated. The behavior of the insulation is most directly responsive to temperature; the light fixture can be viewed mainly as a device that imposes a temperature on the boundary of the insulation and sets the general geometry for heat losses from the insulation. In examining the behavior of the insulation then, it is simpler to replace the light fixture with a constant temperature source and vary that temperature in separate tests to find the minimum value that just produces ignition. In so doing we have somewhat de-coupled the problem relative to what occurs in practice and this must. be borne in mind when the results are used to develop an ignition test method; a constant power source (e.g., a recessed light fixture) will not always behave the same as a constant temperature source although they are nearly equivalent in the almost steady-scace tests used here.

We have stated that heat source geometry is important in that it affects the heat losses from the initially.reacting layer of the insulation. One of the goals of the current work was to demonstrate this quantitatively; a second goal was to ascertain if this behavior could be predicted quantitatively. If we understand the ignition behavior well enough to make quantitative predictions about it, we have a firm basis for going to the next step, i.e., developing a suitable test method for smolder ignition tendency.

The effect of heat source geometry on minimum source temperature to produce ignition was studied for several configurations. These geometries were suggested by real heat sources such as those seen in residential attics but they were simplified to factlitate comparisons with a numerical model of ignition. The various sources were all tested in an "attic mock-up" so that the results would be reasonably transferable to the real world. The details of the sources and the mock-up are given in Appendix I. Determination of the borderline or minimum source temperature for smolder initiation requlred four or more separate tests for each configuration since the border can only be found by go/no-go testing. (In such a test the source temperature is pre-set and held constant; one waits as much as 12 to 24 hours to see if ignttion occurs.)

The minimum ignition temperature for the same insulation was found to vary from $235^{\circ} \mathrm{C}$ to $385^{\circ} \mathrm{C}$ as heat source configuration was altered. The lowest value came from a source that partially surrounds the insulation in a $90^{\circ}$ corner. The highest value is for a hot cable-like source traversing the $8 \mathrm{in}$. insulation bed at mid-depth.

These results were predicted with an accuracy of $10^{\circ} \mathrm{C}$ by a numerical model of the ignition process. The model accounted for heat generation by a zero order reaction and the transfer of that heat to ambient through the insulation. The "one reaction" responsible for ignition in the insulation was shown to be the first overall reaction sequence exhibited 
in thermogravimetry (TG) ànd differential scanning calorimetry. (DSC) studies of the insulation. The source of the heat release in this first overall reaction (cellulose, lignin, etc.) is a subject in need of further study.

Since the model was reasonably successful, it was used to infer a test configuration that should satisfy two requirements: relatively short test time, and ignition temperatures in the same range as those seen in practice with recessed light fixtures. These tend to be mutially contradictory requirements (see Appendix I) but it appears that they can be approximated with, for example, a heat source that is shaped 1ike a-flat-bottomed bowl, having a diameter of about $15 \mathrm{~cm}$ and a depth of about half the diameter.

\subsection{Recommendation's Concerning Smolder Ignition Test Development}

The above configuration is believed to be capable of producing smolder ignition in $a$ nominal insulation at a borderline temperature of about $250^{\circ} \mathrm{C}$ in a one hour test time. Yarborough, et al. (6) found ignition occurs with real light fixtures which achieve peak temperatures of $225-275^{\circ} \mathrm{C}$; such full-scale testing requires up to 24 hours per test.

The output of tests with the above configuration (after several go/no-go applications of it at several temperatures) is the minimum source temperature that just produces ignition (in this test). A single insulation composition thus gives a single number (or a small range, perhaps $5^{\circ} \mathrm{C}$ due to data scatter). By itself, this number is of limited meaning since it is dependent not only on the insulation but also on the test configuration. It is put into perspective by the previous work in this study (Appendix I) and the work of Yarborough et al. (ref. 6). Previous work establishes some correlation between 1gnition temperature in this configuration and the ignition temperatures seen in idealized residential attic heat sources. The work of ref. 6 provides approximate ignition temperatures for real 1 ight fixture exposures. The combination implies that the small-scale test result will be in the same range as that with real light fixtures.

This relation between the possible test method and the real hazard situation is fairly well eștablished but it needs to be strengthened. The problem is two-fold because of the diversity of both light fixtures and insulations. It must be ascertained if:

1) the minimum ignition temperature ranking of insulation compositions depends on the configuration of the light fixture producing ignition.

2) the ignition temperature-based ranking of insulations is substantially the same in the small-scale test and in the real hazard situation.

The first concern is a product of the complex nature of the actual ignition chemistry (represented by one reaction in the model discussed above). Different 1ight fixtures 
comprise differing heat source geometries and so they will each produce differing ignition temperatures for the same insulation. Since the way in which the real oxidation chemistry occurs is somewhat temperature dependent and this dependency may be a function of insulation composition, it is possible that two different light fixtures, if used to rank a series of insulations for smolder. Ignition tendency, could yleld differing ranking orders. If this were so, there clearly would be an ambiguous correlation between a small-scale test method and such realistic full-scale tests. It is necessary to determine if this occurs within some realistic range of both light fixtures and insulation compositions. This calls for choosing a range of insulations and two or three distinctly different light fixtures. The fixtures would then be used in full-scale go/no-go tests where source temperature is monitored in much the same way the small-scale tests are run; each fixture would be used to obtain the minimum source temperature for ignition of each insulation and the rankings from each fixture would be compared. The non-constancy of temperature over the surface of each fixture calls for careful consideration since it poses an ambiguity in the temperature to which the insulation 1 s responding. Obtaining the source temperature distributton calls for rather extensive instrumentation of the tests.

The second concern above arises from the same source, the temperature-variability of the ignition chemistry. Even if the various fixtures above rank the series of insulations in the same order, it must be established that the small-scale test will do the same. This is a much briefer task since the small test is much faster. There would inevitably be quantitative differences (small to large-scale) in the ignition temperatures of the various insulations. Even if this did not alter the ranking order (small to large-scale), these differences should be carefully scrutinized for any implications they may have about relative behavior on the two scales.

If the small-scale test method comes through the above two checks satisfactorily (as expected), it is ready for round robin testing. Success here depends on careful constraints on the design, manufacture and usage of the sma11-scale tester.

The result of all this provides a data base for assessing what constitutes acceptable performance in the small-scale test. One could establish a serles of performance classes with each class encompassing a range of ignition temperatures in the test. The most preferred class would fall entirely above the range of test ignition temperatures that implies ignition in the preceding full-scale light fixture tests. At present, it is not clear that there are any commercial insulation compositions that would fall in this class if its lower temperature bound is based on the most ignition prone light fixtures. Nevertheless, there is incentive to set the levels of acceptability high both because repeated sub-ignition exposures may drive smolder retardants such as boric acid out of the insulation, lowering its ignition temperature, and because there are indications in the literature that wood products may become more ignitable after prolonged (months or years) high temperature exposure (ref. 8, 9, 10). 
If the author's experience with newsprint-based insulations holds true in general, the ignition borders of most insulations in the sma11-scale test may fall in a rather narrow. range of temperatures (within 20 to $30^{\circ} \mathrm{C}$ of $250^{\circ} \mathrm{C}$, for example). This would not mean the test method is deficient, especially if the above checks of. the test against the full-scale hazard are satisfied. This outcome would instead reflect the rather weak effect present smolder retardants have on smolder ignitability. This in turn implies that effective means for fully eliminating the smolder ignition hazard are not yet. in hand. The rather small effect that retardants such as boric acid have on smolder initiation (ref. 1, also Appendix I to this report) is, in a sense, implicit in the fact that smoldering remains a substantial combustion hazard. If really effective retardants were available (at reasonable cost), the hazard would be eliminated. They are.not.

\subsection{Follow-on Hork on Smolder Ignition}

The only smoldering analog that has been studied in depth is carbon oxidation. There exists a substantial body of literature on the effectiveness of various additives in inhibiting this oxidation. Unfortunately, this is likely to be of little or no use in learning to inhibit smolder ignition in cellulosic insulation because the process starts not with oxidation of the carbonaceous char but with much earlier, more complex reactions (ref. 2,3$)$.

Most cellulosic loose-fill insulations are basically ground wood (newsprint). Wood consists of several polymers and various inorganic contaminants. We do not presently know which one (or more) of these components is responsible for the low temperature exotherm that initiates smoldering. One of the major goals of the present work is to ascertain this and then study the sensitivity of this exotherm to varlous additives. We are not assured of finding the means to suppress smolder initiation but pertinent information on lessening. its probability will emerge.

\section{Smolder Propagation}

\subsection{Background}

After smolder is initlated in a cellulosic insulation by some heat source, it typically becomes a self-sustaining process in a manner analogous to a flame. Some of the heat released during ignition and subsequent combustion is transmitted to adjacent elements of insulation, heating them to the point where they too ignite. This process can continue indefinitely, spreading far away from the original heat source, but. it need not do so. Propagation of smolder, like ignition, involves a balance between heat. release rates and heat loss rates. If the balance can be tilted.in favor of the losses, smolder will extinguish. Unfortunately, for all of the practical materials and use conditions with which the author is familiar, the balance favors continuing propagation. From the limited studies to 
date, it appears that current materials will extinguish only in layer thicknesses less than about 6-10 cm (ref. 3).

Smolder propagation is a complex process that has not been extensively studied. Nearly all of the available experimental data are parametric in nature, mainly concerning the effects of such variables as air supply on propagation rate. 'The most extensive parametric study is that due to Palmer (11); however it includes only very limited information on the internal structure of a propagating smolder wave, namely, part of the temperature distribution in a two-dimensional (2-D) smolder wave propagating through a thin layer (1-2 cm) of sawdust: A more detailed study of a simpler system, 1-D forward and reverse smolder propagation through cellulosic insulation, was completed by the present author and a co-worker; a report on that work is in preparation.

\subsection{Objectives}

This limited amount of information on the details of smolder propagation, especially in a realistic configuration, prompted the present work. There are two general objectives. First, to gather evidence on what drives and controls smolder propagation in cellulosic insulation; this clarifies the problem of inhibiting the propagation process. Second, to establish the nature of the buoyantly-driven smolder case; this is a reference or base case for the forced airflow situation where transition to flaming is much more probable.

\subsection{System Studied and Procedures}

The configuration is a thick $(18 \mathrm{~cm})$ horizontal layer of cellulosic loose-fill insulation placed in the same attic mock-up as was used for the ignition tests discussed above. Figure 1 shows this set-up with the igniter and instrumentation used in this propagation study. Since ignition behavior is not part of this study, smolder is initiated as quickly and uniformly as possible on one end face of the insulation bed. This is accomplished with an electrical resistance heater that is formed into an up and down zig-zag pattern with about $2 \mathrm{~cm}$ spacing (see Fig. 1); this is run from a constant temperature controller, typically at $350-400^{\circ} \mathrm{C}$.

Once smolder is initiated in this plane, it is the author's experience that it is always self-sustaining and continues to spread in these thick (18 cm) beds; whether the insulation 1 s retarded or not. The oxygen supply to the spreading reaction zone is by diffusion and natural convection; the forced air flow case will be addressed in the future. The smoke plume flow above the bed is inevitably somewhat disturbed by the necessity of placing the whole mock-up in a laboratory fume hood; there is no direct cross flow over the bed surface, only random eddies that do not appear to comprise a majór disturbance. 
Under these very weak (no forced flow) oxygen supply conditions, the propagation rate of the smolder along the trough formed by the two boards (see Fig. 1) is extremely slow. The smolder reaction zone may require 10-12 hours to reach the other end of the mock-up, $90 \mathrm{~cm}$ away, in the case of a retarded insulation. The rate of movement of this reaction zone is followed by three sets of two thermocouples each, embedded at initially fixed depths in the insulation. These are 36 American wire gage $\left(1.27 \cdot 10^{-2} \mathrm{~cm} \mathrm{dia.)} \mathrm{bare} \mathrm{chromel/alumel}\right.$ thermocouples arranged so as to "float". freely in the insulation. The bed depth decreases as much as a factor of two during smolder wave passage so that these thermocouples must be free to move downward with it to avoid disruption. The thermocouples are carefully put in place during the packing of the insulation bed so that their spacing and initial height are wcll-defined. Given the thermocouple spacing and the temperature time historles at successive points through the bed, one readily calculates the lateral propagation velocity. Typically it is based on the time necessary for the $250^{\circ} \mathrm{C}$ isotherm to pass between successive thermocouple locations.

The structure of the smolder wave is a product of the factors which control propagation. "Structure" means the spatial distribution of temperature, gas phase chemical species and solid phase species. The detalls of the structure can suggest the dominant factors in the propagation process and the relative roles of the first and second stages of heat generation in driving smolder spread. The variables of primary interest are the temperature, oxygen concentration and solid fuel distribution; it is these three on which we have focused.

Resolving a two-dimensional distribution is a much bigger problem than is resolving a 1-D distribution. The most feasible technique for the present problem involved a moveable probe, inserted from above the fuel bed to various known depths. The probe always remained at one longitudinal location (approx. at mid-length of the bed) and the smolder wave moved past the point at a steady rate. Thus measurements (versus depth) made at successive times could be converted, via the propagation velocity, to values at various lengths along the smolier wave. Profiles of temperature and oxygen concentration were obtained in this manner. For temperature the probe was a $0.025 \mathrm{~cm} \mathrm{dla}$. sheath thermocouple (chromel/alume1) which protruded about $1 \mathrm{~cm}$ from a $1 \mathrm{~mm}$ outside dia. stalnless steel tube providing mechanical support. For oxygen the probe was a plece of $1 \mathrm{~mm}$ outside dia. tubing through which a local gas sample was drawn at $4 \mathrm{~cm}^{3} /$ min. A Beckman 778 polarographic oxygen analyzer measured the $\mathrm{O}_{2}$ partial pressure in this sample stream. Both of these probes produced inevitable disturbances, as discussed below.

The solid fuel distribution could not be measured during a test. Instead, after the smolder wave had propagated sufficlently to provide other data, it was extinguished by being smothered with nitrogen. This was carried out as quickly as possible to minimize deviations from the actively propagating configuration. After extinction the bed was sectioned and small samples ( $\mathrm{few} \mathrm{cm}^{3}$ ) were removed from fixed locations. These were ashed at $700-750^{\circ} \mathrm{C}$ in air. From the ash content and knowledge of the nature of the ash precursor, one can 
calculate the fraction of original organic material that remained in each sample. The uncertainties here largely result from ambiguities in ash behavior as discussed below.

\subsection{Discussion of Typical Results}

About one dozen tests of this type have been carried out thus far using a commercial insulation with a proprietary retardant blend, a nominally unretarded material, and that material with $25 \%$ boric acid add-on. The smolder velocity results are summarized in Table I.

Table I

Lateral Smolder Propagation Rates Through

$18 \mathrm{~cm}$ Deep Cellulosic Insulation Layers

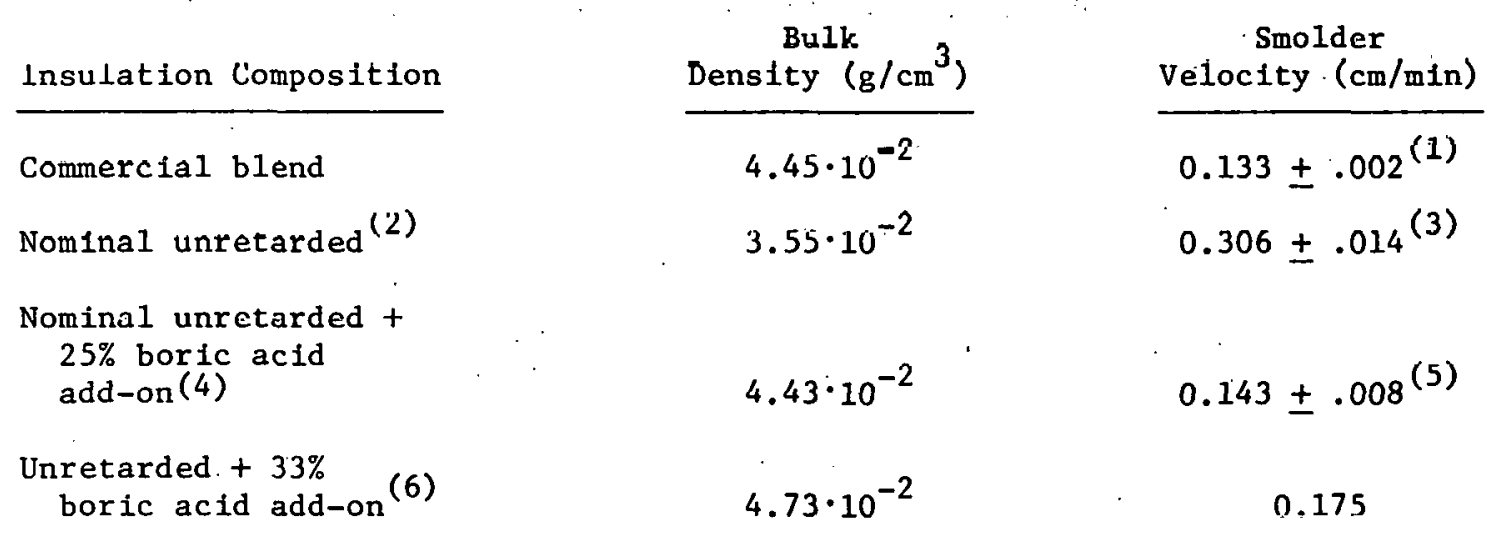

${ }^{(1)}$ Average (t avg. deviation) from three tests; two earlier tests with this material were discarded because the thermocouple arrangement. (vertical insertion) was found to be disruptive.

(2) From same company that made the commerclal blend; ashing indicates this nominally unretarded material actually contains $4-5 \%$ of the retardant mix that is in the commercial blend.

(3) Average ( \pm avg. deviation) of four tests; a fifth test with this materlal transitioned spontaneously to flaming after $2-3 / 4$ hours of smoldering.

${ }^{(4)}$ Boric acid was technical grade, through 200 mesh, milled into insulation for one hour in a roller mill.

(5) Average ( \pm avg. deviation) from two tests.

(6) Material blended by a different manufacturer. 
Note that the bulk densities of the insulation have been adjusted, as retardants were used, to keep the density of the actual cellulosic material approximately constant at about the level in the unretarded case $\left(3.55 \cdot 10^{-2} \mathrm{~g} / \mathrm{cm}^{3}\right.$ or about $\left.2.21 \mathrm{~b} / \mathrm{ft}^{3}\right)$.

In each test four values of smolder velocity were obtained from the time for the $250^{\circ} \mathrm{C}$ isotherm to pass between successive pairs of the six floating thermocouples. While there was typically a $\pm 5 \%$ scatter in these values, it showed no trend with time or position, indicating that the smolder wave was in a steady-propagation state in its journey along the central $36 \mathrm{~cm}$ segment of the bed length (where all measurements were made). The thermocouple traces from the same depth in the wave ( 3 each for two depths) were virtually identical from ambient conditions to more than $500^{\circ} \mathrm{C}$, also confirming the steady state. In Table I, the average of the four values per each test has itself been averaged among tests to give the reported numbers.

It is apparent from Table I that the net effect of either a commercial blend of retardants or a high loading of boric acid alone is merely to slow down the smolder spread process (by about a factior of two); propagation is never brought to a halt. These results confirm our earlier tentative conclusion (ref. 1) based on a smaller and somewhat less realistic experimental set-up. We are interested in learning, however, just where and how boric acid, one of the most effective smolder retardants available, has the effect that it does. This could provide clues as to what is needed to find still better retardants.

The floating thermocouple traces from the two different depths in the wave $(1.8 \mathrm{~cm}$ from the top and $5.4 \mathrm{~cm}$ from the top) provide the first clues that the smolder wave structure is not simply one-dimensional in nature. Fig. 2 shows typical temperature-time traces at the two depths for both the nominally unretarded materlal and that material with $25 \%$ boric acid added on. Note that the time scale is in hours; this is a very slow process. The temperature-time history of a particle of insulation material is clearly different at the two depths in the hed. A shallow particle undergoes a faster rate of heating from 100 to $450^{\circ} \mathrm{C}$, quickly reaching a peak; the subsequent history then depends on the presence or absence of borlc acid. A deep particle undergoes a less rapid Initial heating but there is further sustained heat-up leading ultimately to a higher peak temperature than in the shallow position. These histories reflect the heat transfer and heat generation processes in the moving smolder wave; we'will return to this point below.

One cannot get a full picture of the wave structure from the above results. The moveable probes provided much more data in this regard. Recall that a thermocouple and a gas withdrawal probe were inserted simultaneously from above (about $31 / 2 \mathrm{~cm}$ apart across the width of the wave) to a series of fixed depths. This was done at intervals of ten or more minutes as the smolder wave moved steadily past the probe position. Temperature or oxygen mole fraction versus depth and time were then converted to purely spatial distribution data using the measured smolder velocity to convert time to distance. Finally, the 
loci of various even values of the parameters $\left(\mathrm{e} . \mathrm{g} ., 50,100,200^{\circ} \mathrm{C}\right.$ ) were found by linear interpolation of the recorded results and these points were connected by smooth lines. The resulting profiles are indicators of the spatial structure of the wave. Fig. 3 shows typical results for the nominally unretarded material; Fig. 4 is for that material with 25\% boric acid added on. The top surface profile was obtained by simple measurements from a fixed reference point at successive times.

\subsection{Limitations on Wave Structure Resolution}

Before these profiles are discussed, it is important to note certain Iimitations in them. First, insertion of a thermocouple from above gives results inherently less accurate in this system than are the results from the floating thermocouples; nevertheless the inserted thermocouple was necessary as a means of obtaining closely spaced data points since use of a large number of tloating thermocouples is impractical. Both are comparably small in thermal mass and this is not a problem. However, the probe inserted from above crosses the isotherms at angles as high as $90^{\circ}$. Where these isotherms are closely spaced (region of rapid temperature change) along the thermocouple leads, preferential conduction along these leads will cause the thermocouple junction to be at a temperature different from the local temperature it is supposed to be reading. This is a complex problem to assess quantitatively in the present system. It can be modeled plausibly by analogy to the classic thermowell problem (ref. 12) but the result depends strongly on the effective conductivity of the thermocouple lead and the heat transfer rate to $1 t$; neither of these values is known for this system. The problem is minimized by using a very thin thermocouple; we have used the smallest feasible size $(0.025 \mathrm{~cm}$ dia.) consistent with penetrating the bed without bending. The problem of temperature falsification due to this source is belleved to be minimal except perhaps in the one or two regions of most rapid temperature change along the thermocouple lead. Any falsification results in shifting the apparent position of the isotherms--upward when the thermocouple penetrates down into a gradient whose temperature increases toward the junction and downward in the opposite gradient. The true peak temperature in a small domain will also be underestimated.

The oxygen mole fraction profiles have a limited spatial resolution due to inevitable sampling disturbances. Isokinetic sampling would be the ideal in this system but the local gas tlow velocity is so low here (estimated $\sim 0.04 \mathrm{~cm} / \mathrm{sec}$ ) that the sample probe would have to be about 1-2 $\mathrm{cm}^{2}$ in area to give the needed sample volume flow rate. The necessary sample flow rate $\left(\geq 4 \mathrm{~cm}^{3} / \mathrm{min}\right)$ is set by system response time considerations and other limitations discussed below. To minimize thermal and mechanical disturbances upon probe insertion we have used a gas probe that is a $1 \mathrm{~mm}$ OD by $.75 \mathrm{~mm}$ ID stalnless steel tube drawing at about $4 \mathrm{~cm}^{3} / \mathrm{min}$. The gas velocity into the probe tip is then about $200-300$ times greater than the local flow velocity in the bed in the absence of the probe. The flow disturbance problem has been investigated somewhat (ref. 13) but not out in this very high flow ratio domain. Rough extrapolation of those results would indicate a disturbance out 
to abqut 10 probe radil (here this would equal about $5 \mathrm{~mm}$ ). In the absence of any normal flow in the bed (infinite flow ratio), one can estimate that the $4 \mathrm{~cm}^{3}$ withdrawal in a typical one minute of sampling would come from a sphere of $1 \mathrm{~cm}$ in diameter around the probe tip. We conclude that the oxygen sampling resolution is probably about $\pm 1 \mathrm{~cm}$ (i.e. the probe averages the sample over this domain). Clearly, steep gradients cannot be resolved; the actual gradients in the bed are probably steeper than those shown in Fig. 3 and 4; especially in the upper layers of the bed above the charred material. It was not possible to vary the sampling flow rate appreciably to investigate this question. Greater flow rates caused continual probe clogging problems; lesser flow rates extend the sampling time excessively.

Sampling time is limited by another phenomenon. The bed shrinks as the smolder wave passes through it but the local motions are not only downward, they are also lateral, up to $2 \mathrm{~cm}$ in the unretarded case. This lateral motion is locally inhibited by the probes while they are temporarily in the bed for sampling purposes and the result can be an oblong hole around the probe or even a total fracture across the width of the bed. When this happens, the local conditions no longer are representative of an undisturbed smolder wave. This problem was most severe toward the latter end of early tests, particularly with unietarded insulation. A variety of small accommodations has been developed to minimize the problem but short total immersion time for the probe is vital. One minute at $4 \mathrm{~cm}^{3} / \mathrm{min}$ is needed to purge the gas sampling line and allow the polarographic probe to come to equilibrium.

Figures 3 and 4 also show profiles of the remaining organic material at various positions. As indicated previously, these data were obtained in the extinguished smolder wave by removing and ashing samples a few cubic centimeters in volume. This means that the result obtained is an average over the sampled volume and we cannot get fine resolution of rapidly changing domains. The resolution is comparable to the oxygen probe, about $\pm 1 \mathrm{~cm}$.

Translating the ash content of a solid sample to the local fraction of organic material remaining is done by the following relation.' It is made somewhat complicated because the ash is a retardant residue that could have lost weight during the smolder process and during the ashing of the sample.

$$
\varepsilon=(\gamma \beta) \frac{F_{\text {ro }}}{F_{\text {sw }}} \frac{\left(1-F_{\text {SW }} / \beta\right)}{\left(1-F_{\text {ro }}\right)}
$$

Here $\varepsilon$ is the fraction of remaining organic in the sample, $\gamma$ 1s the weight of smolder altered retardant per unit weight of original retardant, $\beta$ is weight of ash produced per unit weight of smolder-altered retardant, $F_{\text {ro }}$ is the weight of original retardant per unit weight of original insulation $\mathrm{mix}$ and $\mathrm{F}_{\mathrm{sw}}$ is weight of final ash per unit weight of sample from the extinguished wave. Only $F_{E w}$ is measured; $F_{r n}$ is set by the chosen mixture of retardant and insulation. The quantities $\gamma$ and $B$ require a knowledge of the behavior of the retardant as a function of temperature. Furthermore, to apply them correctly to a given sample, one must know to what temperature it has been exposed. 
The retardant mix in our commercial blend is known only in a qualitative sense, though we can infer the probable welght fraction range of the components from published results on retardant effectiveness (ref. 14). From this we can, in turn infer that the commercial retardant would lose about half of its weight by $300-350^{\circ} \mathrm{C}$ and undergo no more weight $10 s \mathrm{~s}$ during the ashing process at $700-750^{\circ} \mathrm{C}$. Thus we estimate that above $300-350^{\circ} \mathrm{C}$ for this system $\gamma=0.5$ and $\beta=1.0$. Since there is a small amount of the commercial retardant blend in our nominally unretarded material, these values were used in converting ash values to values of $\varepsilon$ for the nominally unretarded bed (Fig. 3). The behavior of boric acid alone is much easier to characterize though still subject to some uncertainties. Boric acid undergoes two successive water loss reactions to end up as $\mathrm{B}_{2} \mathrm{O}_{3}$ by about $300^{\circ} \mathrm{C}$. The stolchiometry of this is clear but the complication comes from the volatility of boric acid in a system (i.e. degrading insulation) where both water and methanol are present. . We have ashed known mixtures of insulation plus boric acid and find that some small but significant loss of boron does occur. 'lhe best values presently avallable for the boric actd treated insulations are essentially the same as those above, i.e., $\gamma=0.5$ and $\beta=1.0$ for samples exposed to $300^{\circ} \mathrm{C}$ or more in the smolder wave. Because of ambiguities and scatter in the boron loss aspect, the value of $\gamma$ is probably uncertain within $\pm 10 \%-15 \%$ and this puts an equal uncertainty in the value of $\varepsilon$. Because the retardant transformations may get more complex and time-dependent below $300^{\circ} \mathrm{C}$, we have not yet made any attempt to resolve the remaining-organic profiles below $300^{\circ} \mathrm{C}$ in the smolder wave.

\subsection{Factors Controlling Wave Shape}

Despite this long list of caveats regarding the wave profiles in Fig. 3 and 4, they contain a large amount of useful information. Interpretation of these results is still in progress but several pertinent points can be made.

First, the length of the smolder wave should be noted; it is 30 to $60 \mathrm{~cm} \mathrm{long,} \mathrm{about}$ 2 to 3 times greater than the bed depth. This ratio of wavelength to layer thickness is comparable to that found by Palmer (ref. 11) for sawdust layers a few centineters deep. suggesting that similar factors may control the rate of oxidation over this range of thicknesses. Essentially all realistic smolider configurations appear to be oxygen-limited (see Appendix. II), i.e., the overall rate of oxidation is 1 imited by the rate of $0_{2}$ supply and It increases when that supply increases. I'his appears to be the case here as well; note the extensive domain in the high temperature region of the wave where $0_{2} 1$ s fully depleted. In this horizontal layer configuration, $\mathrm{O}_{2}$ can get to the reaction zone in two ways, by natural convection flow and by diffusion from the surrounding atmosphere. Natural convection flow through the insulation is, of course, quite difficult due to the high specific surface area of the fibers. We can estimate the magnitude of the convective flow velocity. by. applying a balance between flow drag and buoyancy forces. This leads to the following expression: 


$$
v_{B}=\left(\frac{g \rho_{A}}{a_{D}}\right)\left(\frac{\bar{T}-T_{A}}{\bar{T}}\right)\left(\frac{{ }_{A}}{\bar{\mu}}\right)
$$

Here $v_{B}$ is the desired estimate of the buoyant flow velocity in the insulation, $g$ is the gravitational acceleration, $\rho_{A}$ is the ambient air density, $a_{D}$ is the measured drag constant for the insulation, $\bar{T}$ is an average temperature in the smolder region, $T_{A}$ is the ambient temperature, $\mu_{A}$ and $\bar{\mu}$ are the gas viscosities at ambient temperature and at $\bar{T}$, respectively. The drag constant is measured on virgin insulation; it undoubtedly decreases due to mass loss in some portions of the smolder wave. The "average" temperature in the wave is taken as $350^{\circ} \mathrm{C}$; the calculation is not very sensitive to the exact value. Putting this and other typical numbers into the above equation gives $v_{B} \simeq 0.04: \mathrm{cm} / \mathrm{sec}$; the actual values throughout the wave could easily be $\pm 50 \%$ different from this estimate but we are, for the moment, most interested in the leading part of the wave where this value is reasonably appropriate.

Fig. 5 is a sketch of the two $\mathrm{O}_{2}$ supply modes that we wish to compare. The sketch of the convective flow is quite rough; no measurements inside the bed have been possible. The buoyant plume above the hot reaction zone is shifted around considerably by the fume hood flow in actual experiments so the average $o_{2}$ level at virtually all points above the smoldering layer is expected to remain essentially at $21 \%$ (even in less disturbed circumstances this would be true over most of the smolder zone because the plume coming out of the porous layer contracts sharply). Consider the convective inflow of $\mathrm{o}_{2}$ from the left in Fig. 5 compared to the diffusive flow downward from above. The convective $\mathrm{O}_{2}$ flow is approximately

$$
\mathrm{S}_{\mathrm{OC}} \simeq \ell \mathrm{Y}_{\mathrm{OXA}} \vec{\rho} \mathrm{v}_{\mathrm{B}}
$$

The diffusive flow is approximately

$$
\mathrm{S}_{\mathrm{OD}} \simeq\left(\frac{\bar{\rho} \mathrm{D} \Delta \mathrm{Y}_{\mathrm{OX}}}{\ell_{\mathrm{D}}}\right) \ell \text {. }
$$

These are mass flows in $\mathrm{g} / \mathrm{sec}$ per unit width of the smolder layer; $Y_{O X A}$ is the ambient oxygen mass fraction (above the bed). Here we use $l$ the layer depth, as a rough characteristic length both for the convective influx and for the length of the reaction zone affected by these two $\mathrm{O}_{2}$ fluxes. The $\mathrm{O}_{2}$ diffusivity $\overline{\mathrm{D}}$ is evaluated at the average layer temperature above the reaction zone; $\Delta \mathrm{Y}_{\mathrm{OX}}\left(\equiv \mathrm{Y}_{\mathrm{OXA}}\right)$ is the change in $\mathrm{O}_{2}$ mass fraction from the top of the layex to center of the reaction zone. The average $o_{2}$ diffusion length $l_{D}$ is at most equal to the distance from top of the bed to the edge of the $\mathrm{O}_{2}$ depleted region in Fig. 3 or Fig. 4; because of probe volume averaging effects, the actual value of $l_{D}$ is probably less than this. If typical numbers based on Fig. 4 are inserted in the above expressions, we find

$$
\mathrm{s}_{\mathrm{OC}} \simeq 9 \cdot 10^{-5} \mathrm{~g} / \mathrm{sec} \quad \mathrm{s}_{\mathrm{OD}} \simeq 3 \cdot 10^{-4} \mathrm{~g} / \mathrm{sec}
$$


This rough method of calculation probably overestimates the convective $f l u x S_{O C}$ and underestimates the diffusive flux $S_{O D}$. The results suggest (but do not firmly establish) that $\mathrm{O}_{2}$ diffusion is the dominant $\mathrm{O}_{2}$ supply mode in these natural convection conditions (This would change drastically if there was a forced flow through the insulation layer as can occur near the eaves in an attic. Such forced flow can induce a transition.to flaming).

The conclusion that $\mathrm{O}_{2}$ diffusion probably dominates the $\mathrm{O}_{2}$ supply is reinforced by the following rough argument concerning how $\mathrm{O}_{2}$ diffusion would dictate the shape of the reaction zone. Suppose the actual reaction zone was thin compared to the insulation layer (assumption of fast kinetics); then the reaction zone could be considered to be a surface whose shape we want to determine. Consider the $\mathrm{O}_{2}$ requirements and supply to a differential element of that surface; following Gugan (ref. 19)

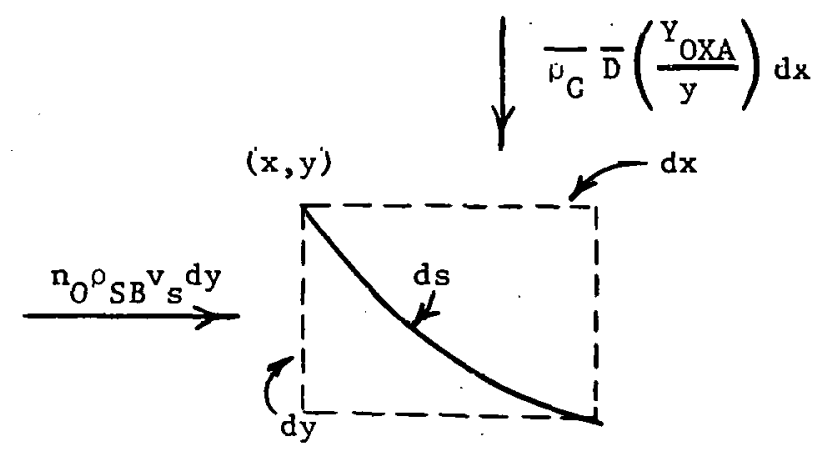

Here the element of surface is of length ds and unit width; it is situated at depth $y$ below the top surtace of the tuel layer. 'l'he layer is smoldering at a steady rate; we can thus assume ds is fixed and fresh fuel comes into this collapsed reaction zone at a rate set by the smoldcr velocity $v_{0}$. The quantity entering ds per second is $\rho_{E B} v_{g} d y$ where $\rho_{S B}$ is the bulk density of the fuel. Oxidation of this fuel requires $n_{0}$ mass of $o_{2}$ for mass of fuel (stoichiometric coefficient). The required $\mathrm{O}_{2}$ must all come from above by diffusion through the layer depth y. Then

$$
n_{O}{ }^{\rho} B^{v_{s}} d y=\overline{\rho_{G}} \bar{D}\left(\begin{array}{c}
Y_{n X A} \\
y
\end{array}\right) d x
$$

This differential equation specifies the shape of the reaction surface by relating $x$ and $y$ on the surface.

$$
y=\left[\left(\frac{2 \overline{\rho_{G}} \bar{D} Y_{O X A}}{{\overline{n_{O X}}}^{\rho_{S B} v_{s}}}\right) x\right]^{1 / 2}
$$

With the origin $(x=y=0)$ at the top of the layer where the reaction surface begins, this specifies a parabolic reaction surface shape: 


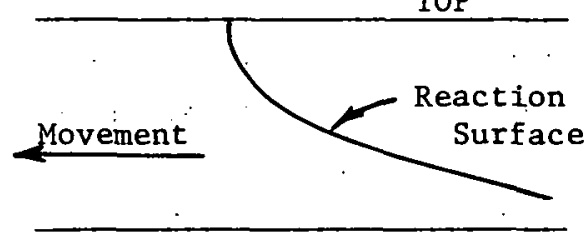

The qualitative similarity of this to the isotherms or organic fraction profiles of Fig. 3 and 4 is apparent. Even though the real reaction zone is thick and there is layer shrinkage, ignored in the above analysis, the similarity of the two profiles lends credence to the assertion that the general shape of the smolder wave is dictated by its dominant $0_{2}$ supply mode, i.e. diffusion from above. One can even use the above simple expression to roughly estimate the length of the smolder wave (by inserting $y=\ell$ ) if $n_{0}$ is known. It can be shown that if $\mathrm{n}_{0}$ is approximated by summing estimates of the convective and diffusive $0_{2}$ supplies (over the whole wave) that go with a measured smolder rate, the predicted value of the smolder wave length is of the correct order of magnitude (but may be off by a factor of two).

\subsection{Some Fffects of Boric Acid}

The reaction zone in reality is not only thick (due to finite rate kinetics), it is comprised of more than one reaction stage. Fig. 6, taken from ref. 1, shows how unretarded and retarded (boric acid) insulation behaves during thermal analysis. There are two broad stages of weight loss and heat release which we will refer.to as char formation (lst stage) and char oxidation. Recall that in Section II it was mentioned that smolder initiation is largely due to the heat released in the char formation stage. It is of interest to determine to what extent these two overall reactions stages play a role in smolder propagation. Inspection of Fig. 6 shows that boric acid does not affect these two stages equally. Rather it is substantially more successful in slowing the heat release rate of char oxidation. The actual oxidation chemistry underlying these two overall heat release/weight loss stages is very likely quite different. The first stage probably involves $\mathrm{O}_{2}$ attack on molecules that still bear substantial resemblance to the orlginal cellulose, lignin, etc.; the second stage probably more closely resembles carbon oxidation. Thus the influence of retardants and catalysts on either stage is 11 kely to be different; the effect of boric acid in Fig. 6 is consistent with this. If we knew that only one stage dominated smolder propagation, efforts at developing better retardants could be more sharply focused. However, as will be seen, the evidence now points at both stages.

Fig. 6 serves to relate insulation weight loss (or fraction of original weight remaining) with heat release stage. It should be noted that although the horizontal axis in F.Ig. 6 ls lemperature, it alone is not an indicator of what stage of weight loss or heat release is achieved. This is because both the heating rate and $0_{2}$ availability history are different in the smolder wave than in thermal analysis. 
The lowest sets of profiles in Fig. 3 and 4 are those of the fraction of remaining organic material. Reference to Fig. 6 gives rough dividing lines between the two reaction stages that can be used to help interpret the remaining organic profiles in Fig. 3 and 4 . A plausible dividing line would be a vertical line dropped to the baseline from the lowest point between the two reaction peaks. The dividing line between heat release stages for the unretarded material occurs approximately at a remaining weight fraction of 0.2 to 0.25 ; for the boric acid retarded material it is more diffuse but roughly 0.3 to 0.35 weight fraction remaining. (Note that the $5^{\circ} \mathrm{C} / \mathrm{min}$ heating rate in $\mathrm{Fig}$. 6 is four.to eight times below the pertinent rates in the smolder wave; this is not believed to have a substantial effect on the dividing lines assigned here.) Both the retarded and unretarded insulations go unambiguously below their respective dividing lines indicating hoth involve first and second stage heat release. The boric acid retarded insulation in Fig. 4 stops at a significantly higher fraction of remaining organic indicating that the boric acid cuts off the last part of the char oxidation stage.

A further indication that boric acid effectively cuts off the final part of char oxidation is shown in the isotherm profiles of Fig. 3 and 4. The "variable" portion of the unretarded temperature profiles is caused by an "afterglow" phenomenon common to cellulosic materials. Here it manifests itself as a dull orange-red glowing region, $1 \mathrm{~cm}$ or more in size, that intermittently and randomly propagates around in the charred residue at the tail end of the smolder wave. This process is particularly dangerous since, when it approaches the partially quenched material that always exists at the boundaries of the smolidere.d inslllation layer, it can generate, and ignite to flaming, pyrolysis gases. This happened spontaneously in one of the tests with our nominally unretarded material, 1.e., transition to flaming in the absence of boric acid need not require a forced air flow. By lessening the probability of transition to flaming, boric acid serves an important safety function even if it is not very effective in retarding smolder initiation or propagation.

Still another indication of the ability of boric acid to retard the latter part of char oxidation came in the sample ashing process used to determine the fraction of remaining organic material. For samples containing boric acid, the final ashing temperature had to be raised from 700 to $750^{\circ} \mathrm{C}$ and the time at that temperature had to be morc than doubled to assure virtually total burn-off of all organic material.

Returning to Fig. 3 and 4, we note again that smolder in both the retarded and unretarded insulations involves both stages of heat release shown in Fig. 6 . Furthermore, there seems to be a somewhat differing distribution of the weight loss (and hence heat release) processes. The second stage weight loss in the unretarded case is concentrated in a thin region at the top of the insulation layer (at least in the first 20-30 cm of the reaction zone). Below that there is a rather extensive region of nearly constant weight fraction. This latter region coincides with the $\mathrm{O}_{2}$ depleted zone. Reaction is suppressed here due to a lack of $\mathrm{O}_{2}$. The incoming $\mathrm{O}_{2}$ from above is being totally consumed by the char 
oxidation. The $\mathrm{O}_{2}$ from the region ahead of the wave is evidently being totally consumed by the first stage of oxidation, probably just inside the indicated line (actuaily a few millimeter zone) of color change in the insulation. It should be noted that the $0_{2}$ stoichiometry of the two stages is almost certainly not equal. An estimate is available for the first stage (ref. 15), $0.3 \mathrm{~g} \mathrm{O}_{2} / \mathrm{g}$ fuel consumed; the value for the second stage is believed to be higher in approximate proportion to its higher heat release (ref. 1), 1.e., about six times that of the first stage.

With boric acid there are similar features in the weight loss process but they are modified by the slower kinetics of char oxidation. There is now a rather thick region $(\sim 2 \mathrm{~cm})$ at the top of the insulation layer that is partialiy quenched, 1.e., the we1ght fraction remaining stays up around 0.25 . This thicker quenched region is due to a shift in the local rate of heat loss versus heat generation because of the slower char oxidation. Below this the char oxidation process stops at about 0.16 weight fraction again because the boric acid has retarded the oxidation kinetics to the point where the achievable heat release rate, balanced against the inevitable (though here fairly slow) heat loss rate, cannot produce temperatures capable of consuming the remaining char in the time available, even though $\mathrm{O}_{2}$ is available. Below this kinetically retarded region is a layer of partial char oxidation and, apparently, some latter part of the first stage heat release as well. The initial part of the first stage heat release is again occurring near the color change line but it is terminated by consumption of the slow $0_{2}$ supply from the unburned region of the material.

\subsection{Estimate of Heat Release Distribution}

If the available temperature data had a finer spatial resolution, one could back out the heat release distribution quantitatively. This is an established procedure for.simpler systems such as laminar flames (ref. 16, ref. 17). Since it requires both first and second derivatives of the temperature distribution, the data must be much more finely spaced than that used in Fig. 3 and 4. We do, in fact, have very good data from the floating theimucouples placed in the bed but there is one substantial limitation on that data: it provides a detailed temperature history only along two particle paths through the smolder wave, a shallow path and a decp path (see FIg. 2). It cannot provide data on the full 2-D heat release distribution. However, the shallow thermocouple path through the wave happens to follow a particle whose thermal history is nearly one-dimensional (1-D) because it moves perperdicular to the ieotherms frnm about $100^{\circ} \mathrm{C}$ to nearly $500^{\circ} \mathrm{C}$. For the particle to follow a 1-D history, it must also not be greatly influenced by convective heat carried in the gas since the gas crosses the particle path at varying (unknown) angles. It can be shown, using the previous estimate of the gas velocity, that convective transport to a particle following the shallow thermocouple path is only about $15-20 \%$ of the conductive heat flux it sees.

This and other necessary approximations limtt the accuracy of what follows but the result is still informative. 
When the gas convective $f l u x$ is neglected, a fuel particle proceeding on a path normal . to the isotherms of Fig. 3 or 4 obeys the following energy balance equation

$$
\frac{\mathrm{d}}{\mathrm{ds}}\left(\lambda_{\mathrm{s}} \frac{\mathrm{dT}}{\mathrm{ds}}\right)-\rho_{\mathrm{SB}} \mathrm{v}_{\mathrm{s}} \mathrm{c} s \frac{\mathrm{dT}}{\mathrm{ds}}+\dot{\mathrm{Q}}=0
$$

Here the derivatives are taken along the direction of the particle path, $v_{s}$ is the speed of movement along that path which we take equal to the smolder spread velocity (somewhat in error near the high temperature end where bed shrinkage adds another velocity component); $Q$ is the local heat effect in $\mathrm{cal} / \mathrm{cm}^{3} \mathrm{sec}$ and it can be endothermic or exothermic. Note that the equation applies to a particle moving through a stationary smolder wave at the smolder velocity. The effective conductivity of the insulation $\lambda_{\mathrm{s}}$ undoubtedly increases somewhat with temperature as the material degrades and a radiative transfer component (fairly small in this material) adds in. Because of limited data, we are forced to take a constant value of $\lambda_{3}$, using the data of ref. 18 to estimate a value at a mean temperature of about $200^{\circ} \mathrm{C}$. Finally we convert from length $s$ to time $t$ by using the measured smolder velocity and the above equation, solved for $\dot{Q}$ becomes

$$
\dot{Q}=\left(\rho_{S B} C_{s}\right) \frac{d T}{d t}-\left(\frac{\lambda s}{v_{s}^{2}}\right) \frac{d^{2} T}{d t^{2}}
$$

The time derivatives are to be taken on the temperature-time histories for the shallow thermocouples shown in Fig. 2 .

Despite the very smooth appearance of the data in Fig. 2, it was obtained with a digital recorder that rounded the temperatures to the nearest degree. If one attempts. to use the raw data to calculate $\dot{Q}$, one finds the fitter in the second derivative causes wild variations in $\dot{Q}$ (though the average behavior is consistent with that deduced below). A polynomial regression routine was used to fit smooth curves through the data and permit smooth differentiation. The best fits (fraction of a degree) to the original digital recorder data were obtained if the temperature history was broken into three or four segments and fitted piecemeal. However this invariably caused apparent discontinuities in $?$ versus temperature because the second derivatives, in particular were not continuous acroșs the juncture of any two fitted segments. Finally we used a one or two segment fit to the whole range from about is to nearly $500^{\circ} \mathrm{C}$. The fits are very good except at the ends of the interval. The results are shown in Fig. 7 where the fitted temperature-time history and the calculated $\dot{Q} v s$. $T$ are shown for the retarded and unretarded cases.

The pattern of $\dot{Q}$ vs. $\mathrm{T}$ is qualitatively the same for both the untreated and boric acid treated insulation. That is, both show a low temperature endothermic region that fades out to be replaced by a higher temperature exotherm which in turn tends to zero in the neighborhood of $500^{\circ} \mathrm{C}$. These can be integrated to give the total heat effect as shown in Table II. 
Table II

Summary of Integrated Heat Effects Along 1-D

Particle Path Through Smolder Wave

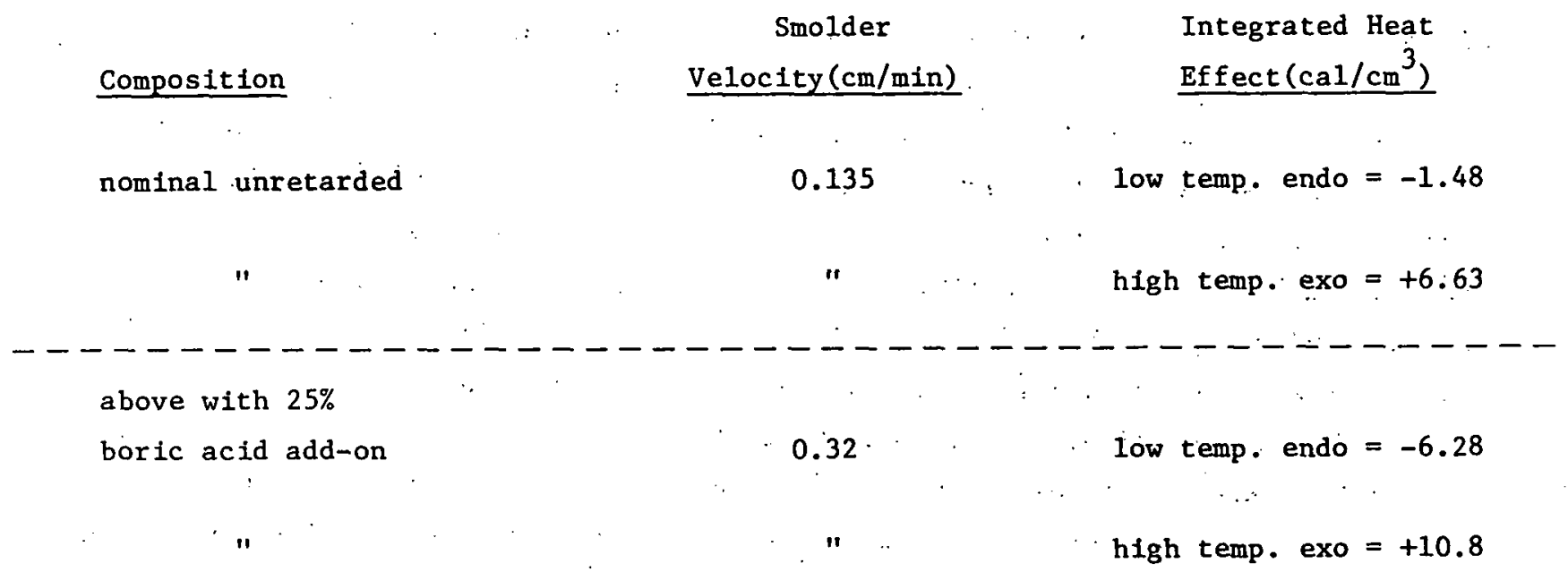

Direct comparison of this heat effect pattern with that 1 . Fig. 6 is not appropriate; we will relate the two below. The low temperature exotherm is initially due to water vaporization in both the retarded and unretarded cases. Note in Table II that the integrated endotherm is much larger in the retarded case. Because of the various approximations that went into calculating these numbers they must be used with caution. However, it is plausible that the endotherm be larger in the retarded case. The equilibrium molsture content of the retarded insulation at room conditions is about $50 \%$ larger than the nominally unretarded material. Furthermore, we noted previously that borlc acid undergoes two successive dehydration reactions below $300^{\circ} \mathrm{C}$. We estimate that these require nearly 200 calories per gram of $\mathrm{H}_{3} \mathrm{BO}_{3}$ and the retarded insulation $1 \mathrm{~s} 20 \%$ by weight borlc acid. This makes the continuing net endothermicity up to about $200^{\circ} \mathrm{C}$, seen in the upper half of Fig. 7 , plausible in the retarded insulation.

It should be noted that the molsture level at the leading edge of the smolder wave can be well above the starting, room temperature equilibrium value. The wave drives water ahead of it and it accumulates until the rate of deposition due to forward wave movement is balanced by the outflow of water vapor due to buoyancy. There is a rather damp region at the front of the wave that tends to stick to the temperature and gas flow probes.

Note that the endothermicity of water vaporization and retardant degradation is comparable in magnitude to the exothermic effects. This implies that these two heat sinks have a substantial impact in slowing the rate of smolder spread. The greater endotherm in the boric acid treated material could be a significant part of the reason for the slower smolder spread in this case. 
The net exotherms in the two cases (Table II) contain an unexpected feature--that for the retarded case is larger than the unretarded case. This may be a false result of the various approximations employed here; this point can be better studied in the simpler 1-D smoldex system which we have available. Note that the net heat effect (algebraic sum of endo- and exothermic effects) is slightly larger for the unretarded material.

The net exotherms shown in Table II are not the total heat released by the particles being followed. Inspection of the particle path shown in Fig. 4, for example, shows that the temperature-time history for the retarded material in Fig. 7 ends when the remaining organic weight fraction is still about 0.30 to 0.35 ; reference to Fig. 6 shows that this corresponds approximately to the end of the first stage of heat release. This is roughly true for the unretarded material as well. Part of the reason for the drop off in heat release near $500^{\circ} \mathrm{C}$ is then kinetic--the next stage of oxidation is somewhat more difficult; however, the major reason is almost certainly the lack of $\mathrm{O}_{2}$ at that point in the smolder wave. Inspection of Fig. 4, for example, shows that the particle path runs into the $0_{2}$ depleted zone as the particle approaches $500^{\circ} \mathrm{C}$.

The portion of the smolder wave shown in Fig. 7 is a reverse smolder (or co-current) part of the wave (see Appendix II for a description of this terminology). The rest of the wave that follows, in which the char ts oxidized by $\mathrm{O}_{2}$ diffusing from above the insulation layer, is a forward smolder (or counter-current) part of the wave. This dichotomy between forward and reverse sections is inherent in the wave structure (which is in turn a result of the $\mathrm{O}_{2}$ supply modes, as discussed above) but there does not seem to be any fundamental reason why the first and second stages of oxidation should fall completely within one section or the other.

It is of interest to cast the exothermic heat in Table II in a form more comparable with the results of thermal analysis. By dividing by the bulk density of the insulation, we get the heat release in calories per gram of insulation. We use the initial bulk density of organic material $\left(3.55 \cdot 10^{-2} \mathrm{~g} / \mathrm{cm}^{3}\right)$; this ignores the slight shrinkage that occurs along the particle path and refers the heat effect to the mass of starting material. When the DSC results of Fig. 6 are integrated and similarly referred to the mass of starting material, we get about $1000 \mathrm{cal} / \mathrm{g}$ for the unretarded material and about $800 \mathrm{cal} / \mathrm{g}$ for the treated material (first oxidation stage). On the other hand, the exotherms in Table II give about $190 \mathrm{cal} / \mathrm{g}$ for the unretarded material and $245 \mathrm{cal} / \mathrm{g}$ for the boric acid treated material. Even allowing for the fact that the derived heat effects in Table II could be off by $2 x$ due to various approximations, it appears that less heat is released in the first oxidation stage than is available according to the DSC results. This is not unexpected; the probable explanation lies in an aspect of the cellulosic material's response to heating that is discussed next. 
As explained in ref. 1, the early stages of degradation of this material, like those of many others, can be represented by two competing overall reactions

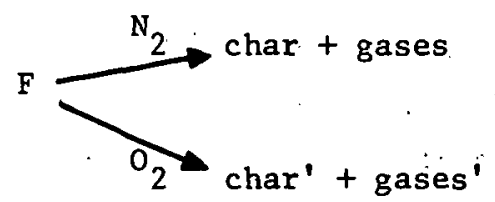

The upper pathway requires no $\mathrm{O}_{2}$ and is weakly endothermic; the lower pathway is exothermic. The balance between the two is a function of the local $o_{2}$ concentration (and the rate of heating). In the DSC results of FIg. 6 , the $0_{2}$ level is constant at $21 \%$. Fig. 3 and 4 show that it is decreasing from $21 \%$ to zero along the particle path we have been examining. This shifts the above balance in favor of the non-oxidative pathway and cuts down the evolved heat (mainly by removing fuel from the lower pathway).

Inspection of the $\mathrm{O}_{2}$ and remaining weight fraction profiles in $\mathrm{Fig} .3$ and 4 shows another consequence of this $\mathrm{O}_{2}$ dependent competition. Particle paths lower in the layer than the shallow one we have been considering undergo the first stage of degradation at lower and lower levels of $\mathrm{O}_{2}$ because they are farther in under the "overhanging" wave structure where $0_{2}$ diffuses at slower and slower rates (longer diffusion path). We infer that there is a continually decreasing contribution from first stage oxidative heat release with increasing depth in the insulation layer. It is interesting to speculate that smolder in a low porosity material with the same chemical characteristics (e.g., solid wood or particle board) would proceed with no practically significant contribution from first stage heat release because $\mathrm{O}_{2}$ could not penetrate the fuel. from the front of the wave as $1 t$ does here.

\subsection{Summary of Wave Structure Findings}

We have found a complex smolder wave structure that depends on a shifting balance of heat release from both stages of oxidation of the cellulosic fuel. At the leading edge of the smolder wave, which extends forward in the shallow part of the Insulation layer, the propagation process appears to. be heavily dependent on the first stage of oxidation even though it does not benefit from the full amount of heat avallable in this stage.

However, even here there is a dependency on heat fed forward from the char oxidation process; this is indicated by the fact that a steady-state wave structure is quickly reached with both stages of oxidation moving forward together. The further back one gets in the wave (and the deeper in the fuel layer) the more the local heat release is dominated by char oxidation. Furthermore, the char oxidizing there (toward rear of wave) is predominantly a pyrolytic rather than nxidative char, (Differences between these chars have not yet been explored.) 
Boric acid cuts the smolder wave speed by about a factor of two. It does this through at least four effects. First it increases the equilibrium moisture content of the insulation. This, plus the second effect, the endothermicity of the boric acid dehydration process, puts a substantial heat sink on the front end of the smolder wave, slowing the rate at which its heat generation can warm up new material. The two remaining effects are kinetic: boric acid slows the rate of both the first and second oxidation stages. Its effect on the first stage (presumably involving $\mathrm{O}_{2}$ attack on polymers that still resemble the original components of wood) is minimal. Its effect on the second oxidation stage ( $0_{2}$ attack on the char left by the first stage) is considerable but still insufficient to let heat losses quench the whole process. However, by suppressing the very end of the char oxidation stage, the dangerous process of afterglow is prevented. This appears to preclude spontaneous transition to flaming combustion in buoyant air flow conditions (but not in forced air flow conditions).

We now have further motivation to learn more about the nature of the first oxidation stage (recall that it is also responsible for smolder initiation). This is a current target of study; the results should help in efforts to retard its occurrence. We also have a clear picture of the buoyantly-driven smolder process which is the starting point for transition to flaming as forced air flow is introduced. The complex structure of the wave implies that it may have an equally complex response depending on the location and direction of the forced air flow. We will explore some of these effects in our current work as well.

\section{Reforences}

[1] Ohlemiller,. T. and Rogers, F., "Smoldering Combustion Hazards of Therma1 Insulation Materials," Oak Ridge Nationa1 Laboratory Report ORNL/Sub-7686/1, July 1980.

[2] Rogers, F. and Ohlemiller, T., "Cellulos1c Insulation Material.. I. Overall Degradation Kinetics and Thermochemistry," Combust. Sci. Tech., Vo1. 24, No. 3 and 4, 1980.

[3] Ohlemiller, T. and Rogers, F., "Cellulosic Inșulation Material. II. Effect of. Additives on Some Smolder Characteristics," Combust. Sci. Tech., Vo1. 24, No. 3 and 4, 1980.

[4] Gross, D., "A Preliminary Study of the Fire Safety of Thermal Insulation for Use in Attics or Enclosed Spaces in Residential Housing," National Bureau of Standards Report NBSIR 78-1497. July 1978.

[5] Zicherman, J. and Fisher, F., "Fire Protection Problems Associated with Cellulose Based Insulation Products," Society of Fire Protection Engineers Technology Report 78-7, May 1978.

[6] Yarborough, D. Yoo, K. and Konen, P., "Recessed Light Fixture Test Facility," Oak Ridge National Laboratory Report ORNL/Sub-7504/3.

[7] Issen, L., "Fire Performance of Loose Fill Cellulosic Insulation in Residential Occupancies - A Progress Report," National Bureau of Standards Report NBSIR 80-2085, August 1980. 
[8] Schaffer, E., "On Smolder Initiation In Cellulosics Under Prolonged Low Level Heating," Fire Technology.

[9] McGuire, J., "Limiting Safe Surface Temperature of Combustible Materials," Fire Technology, August 1969.

[10] U.S. Forest Products Laboratory, "Ignition and Charring Temperatures of Wood," Forest Products Laboratory Report No. 1464 (revised), undated.

[11] Palmer, K., "Smolderlng Combustion in Dusts and Fibrous Materials," Combust. Flame I, 1957 , p. 129.

[12] Eckert, E. and Drake, R., Analysis of Heat and Mass Transfer, McGraw Hill, New York 1972, p. 75 ff.

[13] Fristrom, R. and Westenberg, A., Flame Structure, McGraw-Hill, New York, 1965, p. 190-191.

[14] Day, M. and Wiles, D., "Combustibility of Loose Fiber Fill Cellulose Insulation: III. Evaluation of the Borax: Boric Acid: Aluminumi Sulphate System," J. Cons. Prod. Flamm. 6, June 1979, p. 105.

[15] Lucca, D., "A Comparative Experimental Study of Co-Current and Counter-Current Smolder Propagation," MSE thesis, Mechanical and Aerospace Engineering Dept., Princeton University, March, 1981.

[16] Fristrom, R, and Westenberg, A., op. cit, p. 85.

[17] Levy, A. and Weinberg, F., "Optical Flame Structure Studies: Examination of Reaction Rate Laws in Lean Ethylene-Air Flames," Combust. Flame 3, 1959, p. 229.

[18] Tye, R., "Heat Transmission in Cellulosic Fiber Insulation Materials," J. of Testing and Evaluation 2, No. 3, p. 176 .

[19] Gugan, K., "Natural Smolder in Cigarettes" Combust. Flame 10, June 1966, p. 161. 


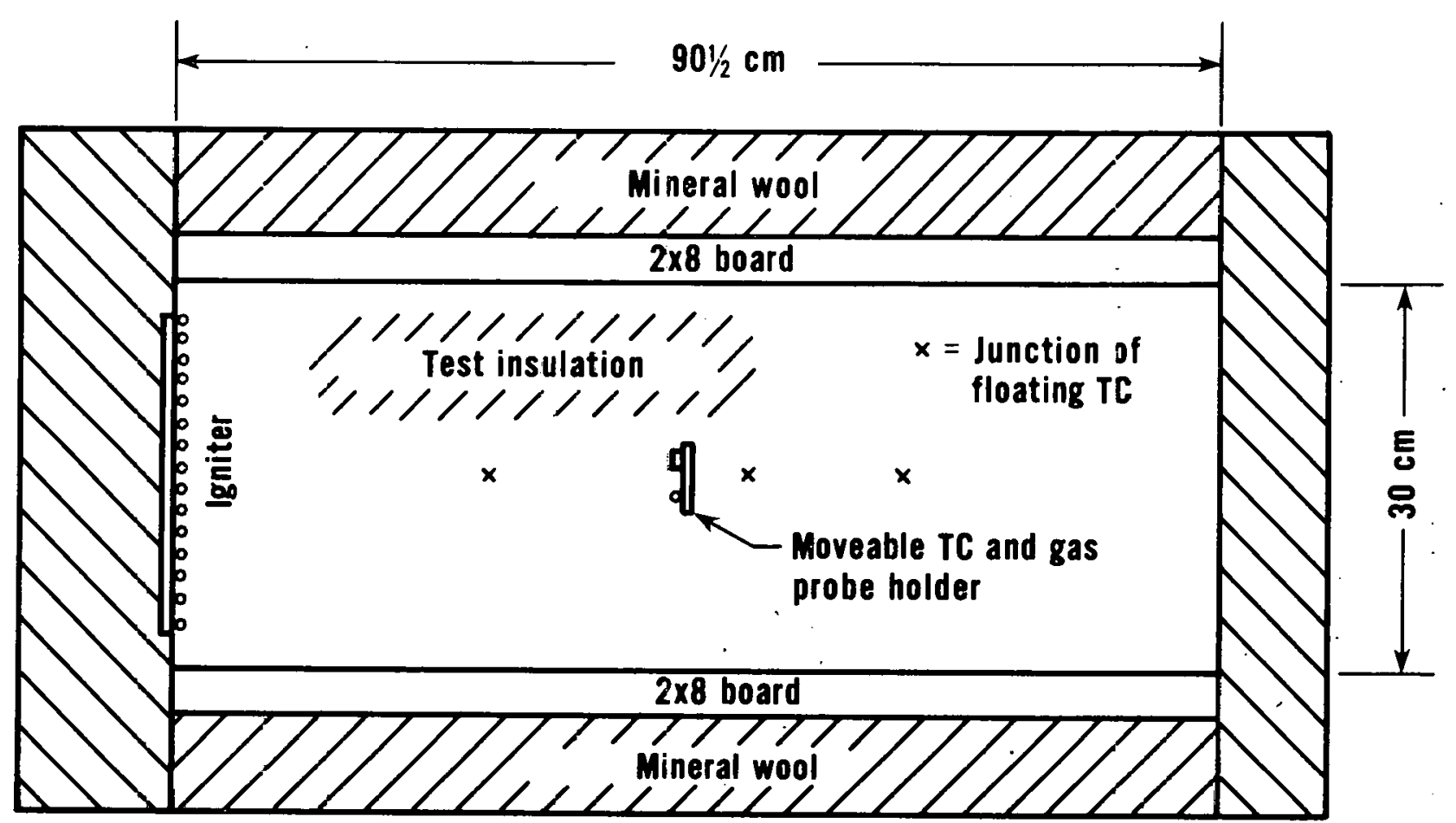

TOP VIEW

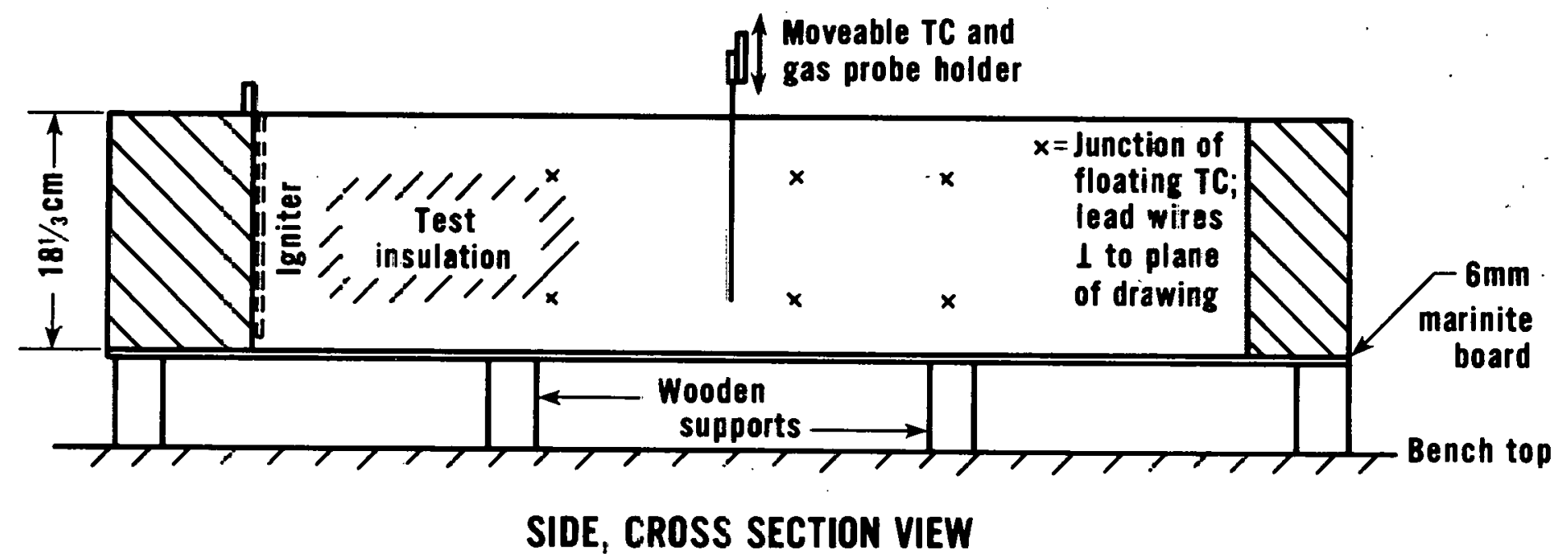

Fig. 1 Attic nock-up adapted for snolder propagation studies. Eighteen centimeter deep insulation 1ayer sits in trough between two $2 \times 8$ pine boards. Ignition occurs uniformly on left end and prozagation achieves a steady state by the time it reaches the first set of floating thermocouples (TC's). 

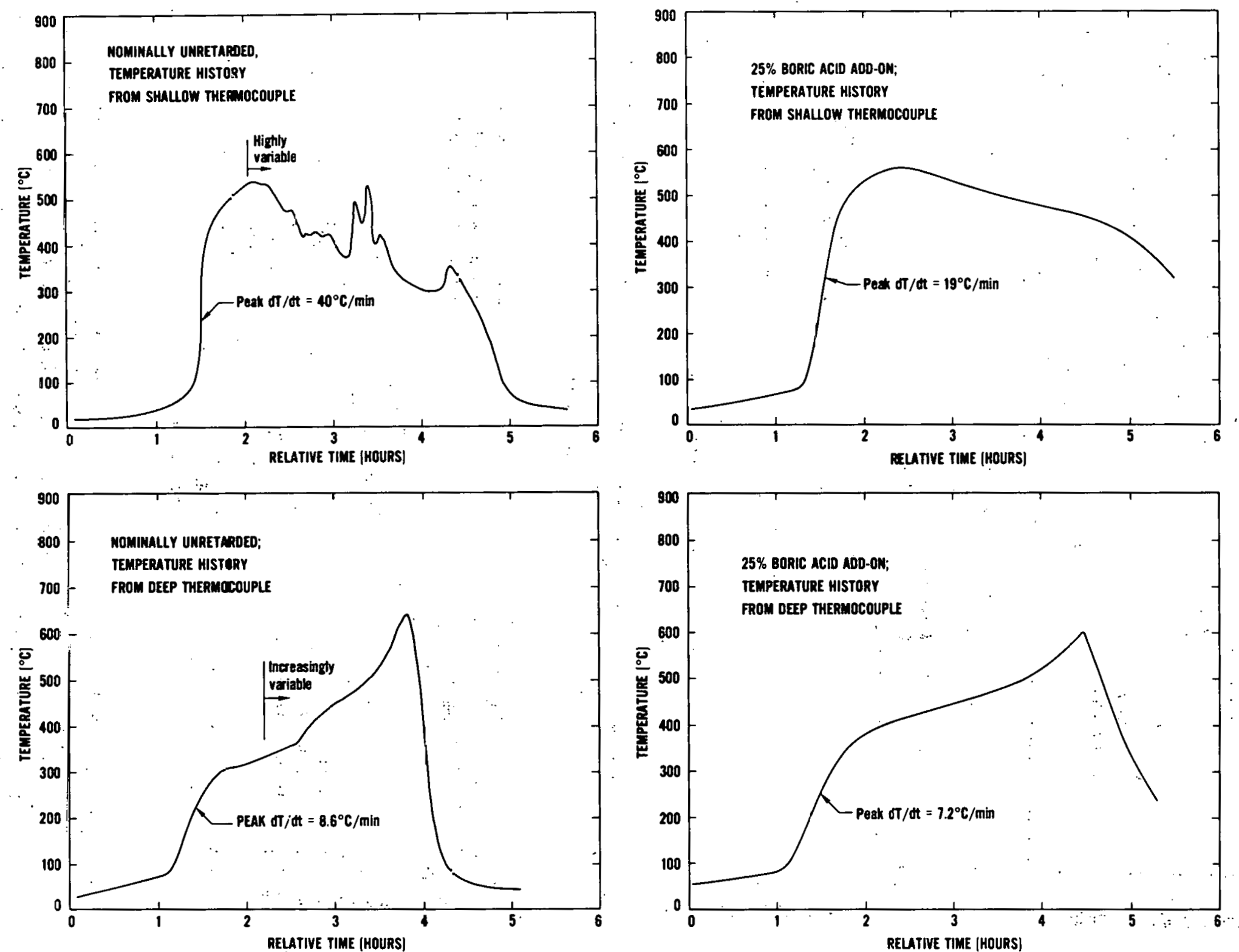

Fig. 2 Typical profiles from floating thermocouples at different depths in the insulation bed. Shallow means TC was initially $13.7 \mathrm{~cm}$ from the bottom; deep means TC was initially

$4.6 \mathrm{~cm}$ from the bottom. The variable portion of the unretarded temperature-time profiles was inflienced by a meandering afterglow region. 

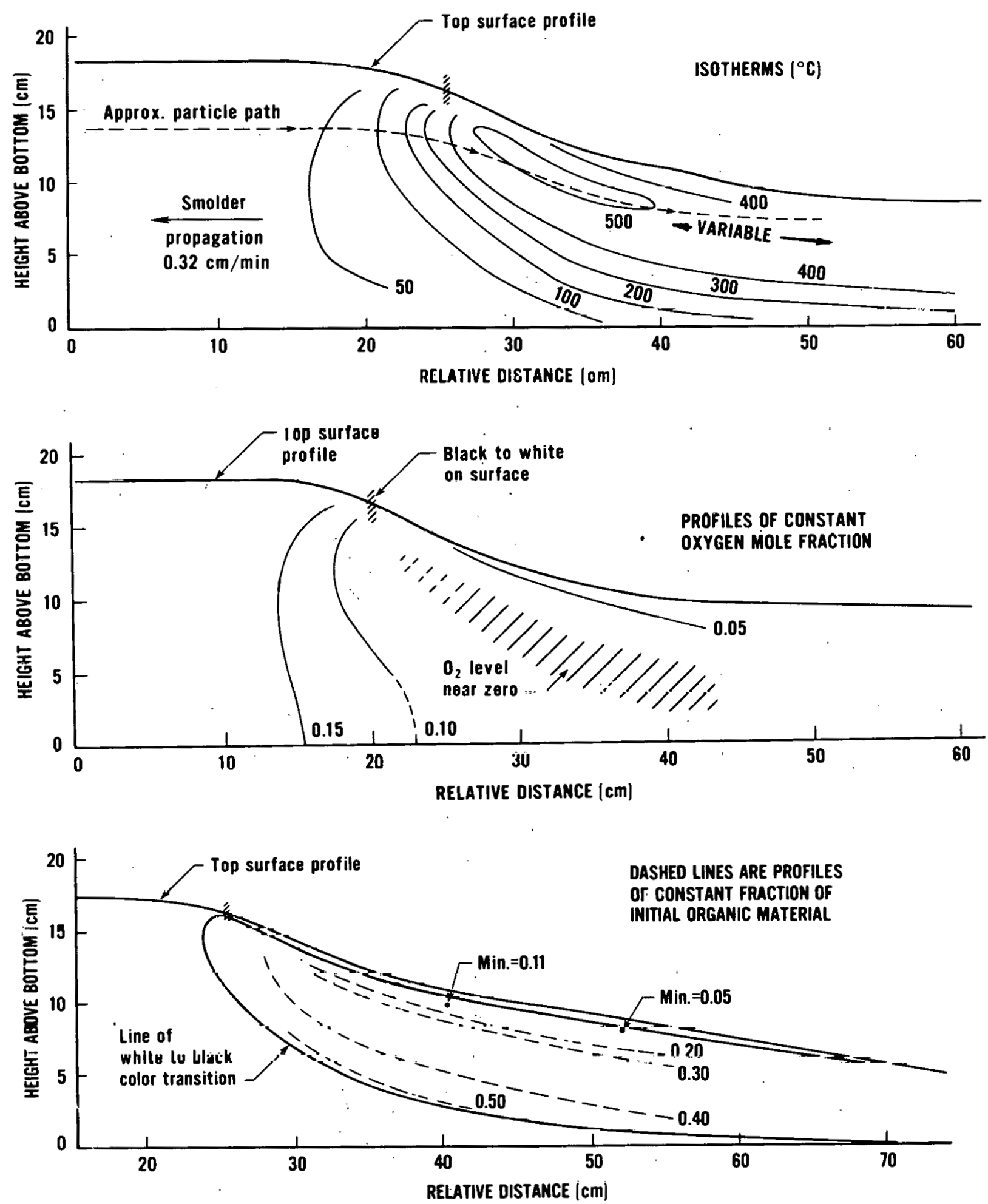

Fig. 3 Cross-sectional snapshot of steady-state smolder wave structure in nominally unretarded insulation. Profiles of temperature, oxygen mole fraction and fraction of remaining organic material superimposed on cross-section of insulation depth versus distance. Note that bottom graph is shifted left about $15 \mathrm{~cm}$ relative to the upper two graphs. 

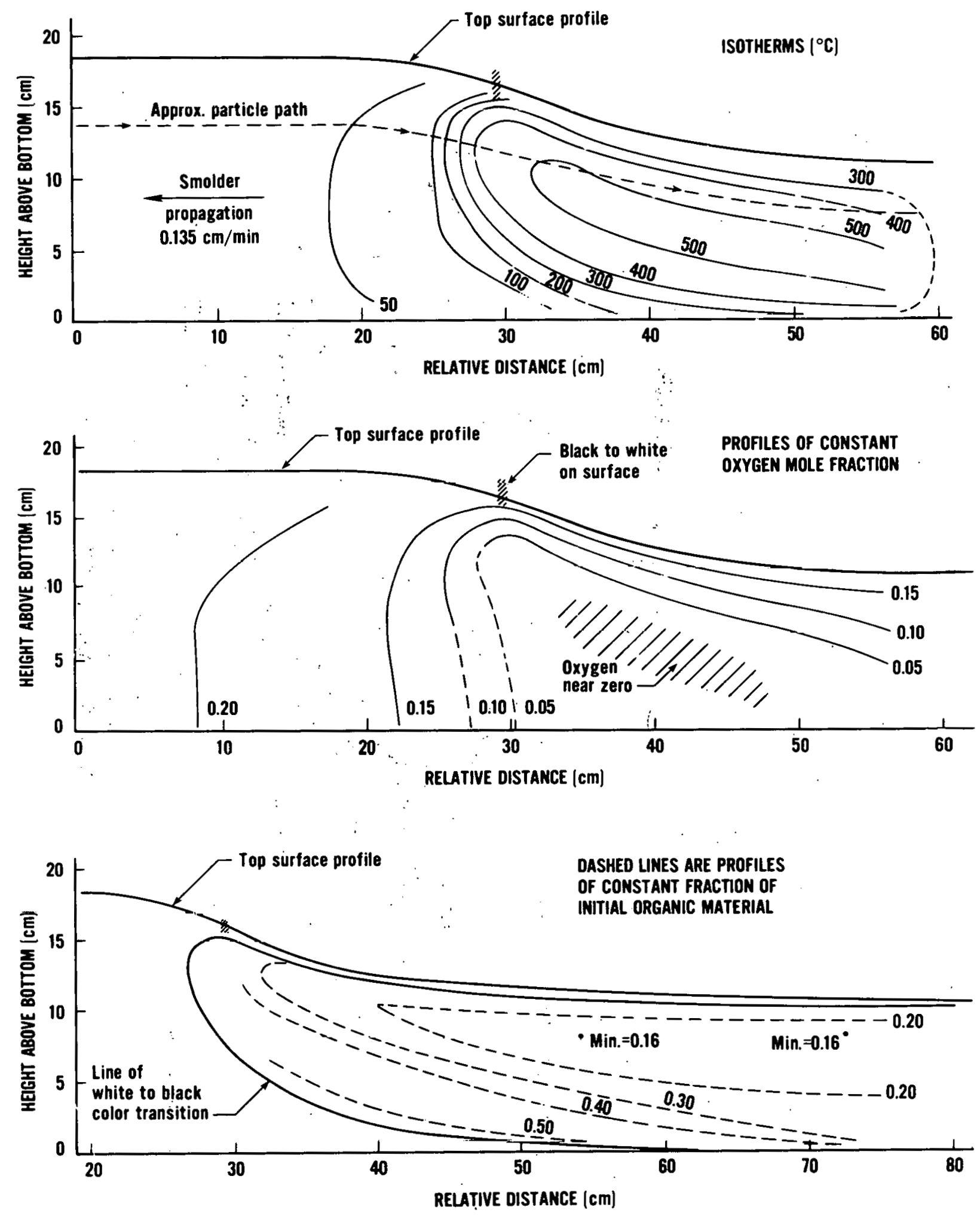

Fig. 4 Cross-sectional snapshot of steady-state smolder propagation in insulation with $25 \%$ borir acid add-on. Profiles of temperature, oxygen mole fraction and fraction of remaining organic material superimposed on cross-section of insulation depth versus distance. Note that bottom graph is shifted left about $20 \mathrm{~cm}$ relative to the two upper graphs. 


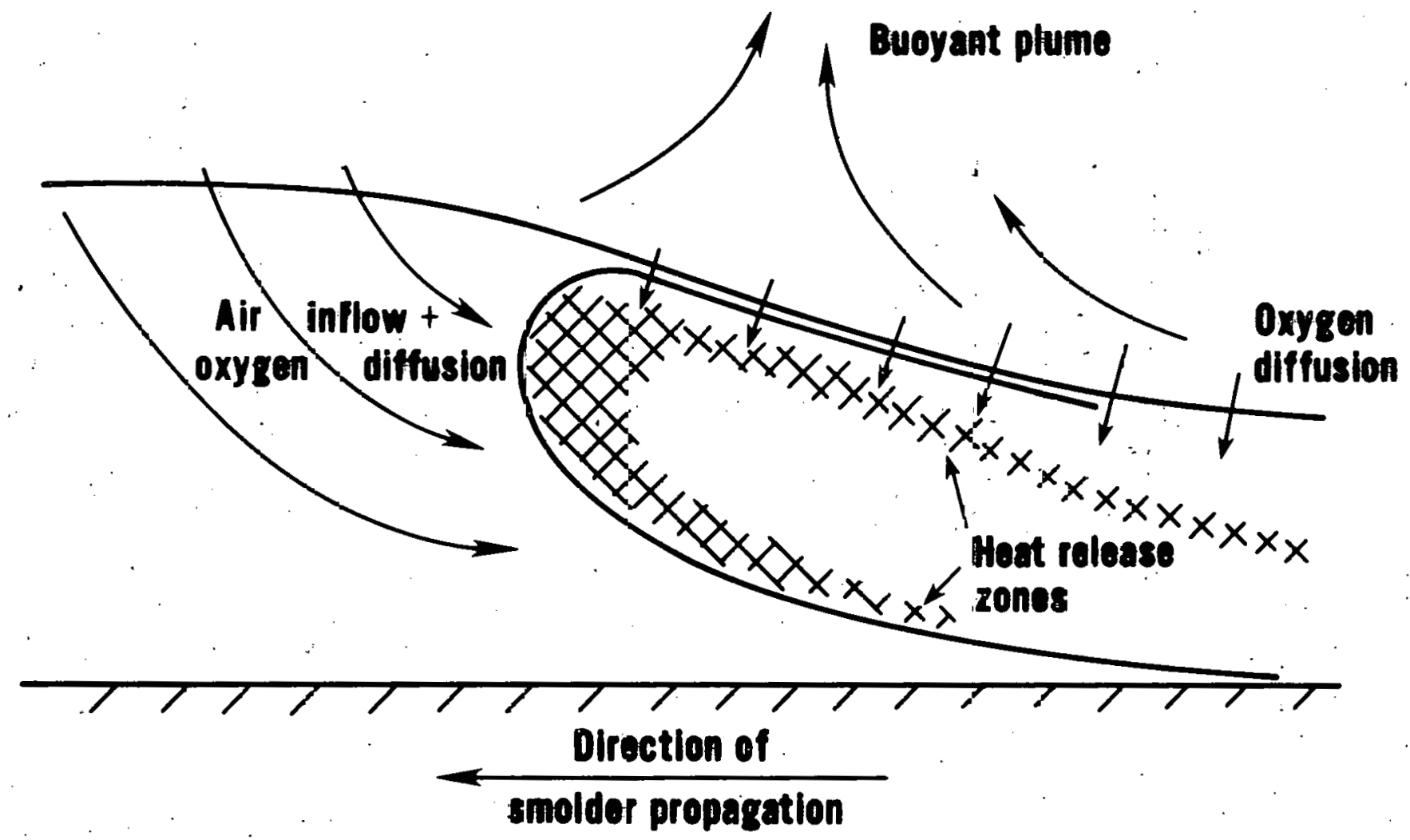

Fig. 5 Sketch of oxygen inflow paths and heat release zozes in spreading smolder wave, inferred from analysis of wave structure profiles. 


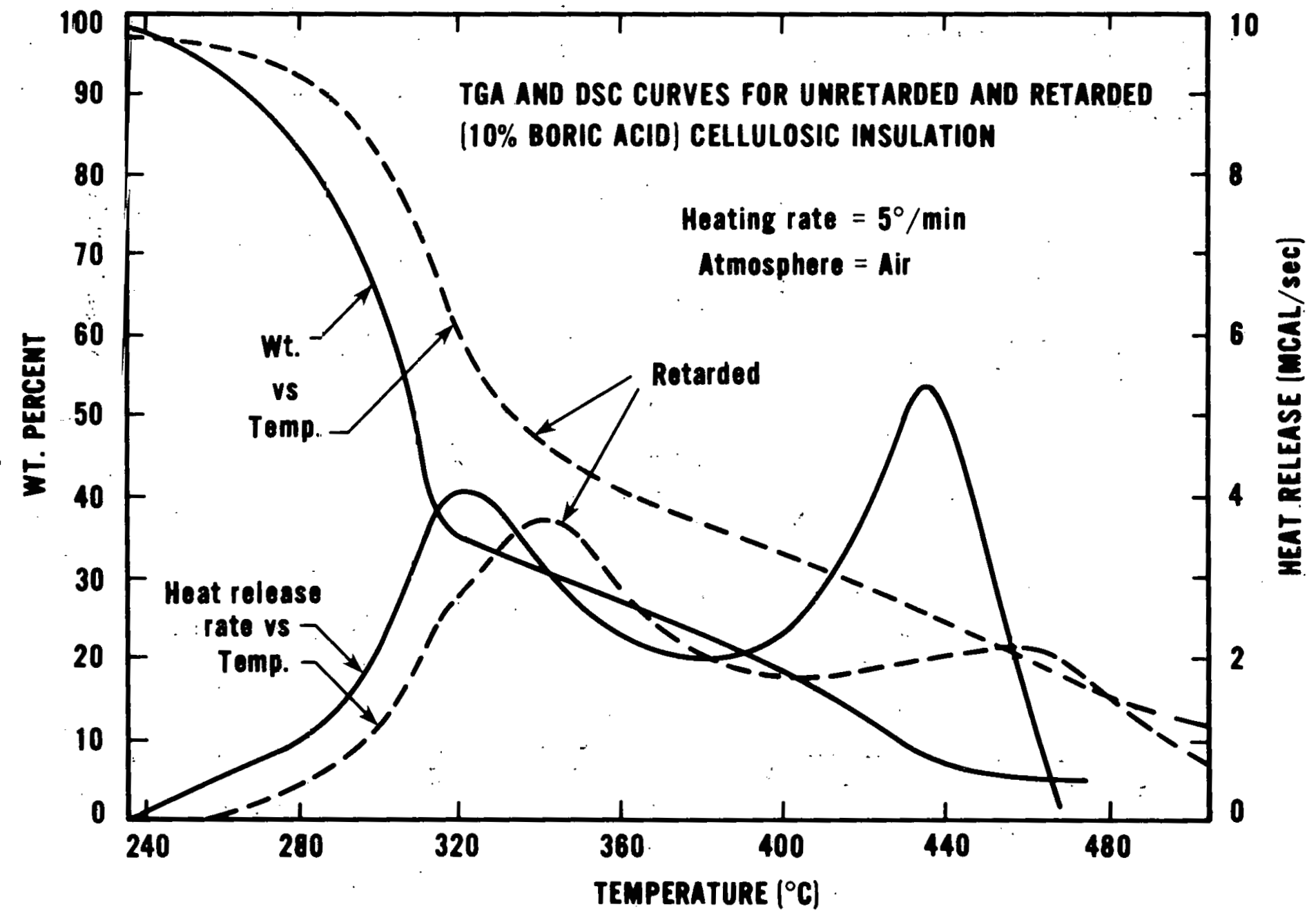

Fig. 6. Thermal analytical results for unretarded and boric acid-retarded insulation. Note two broad, overlapping stages of weight loss and heat release with both compositions. 

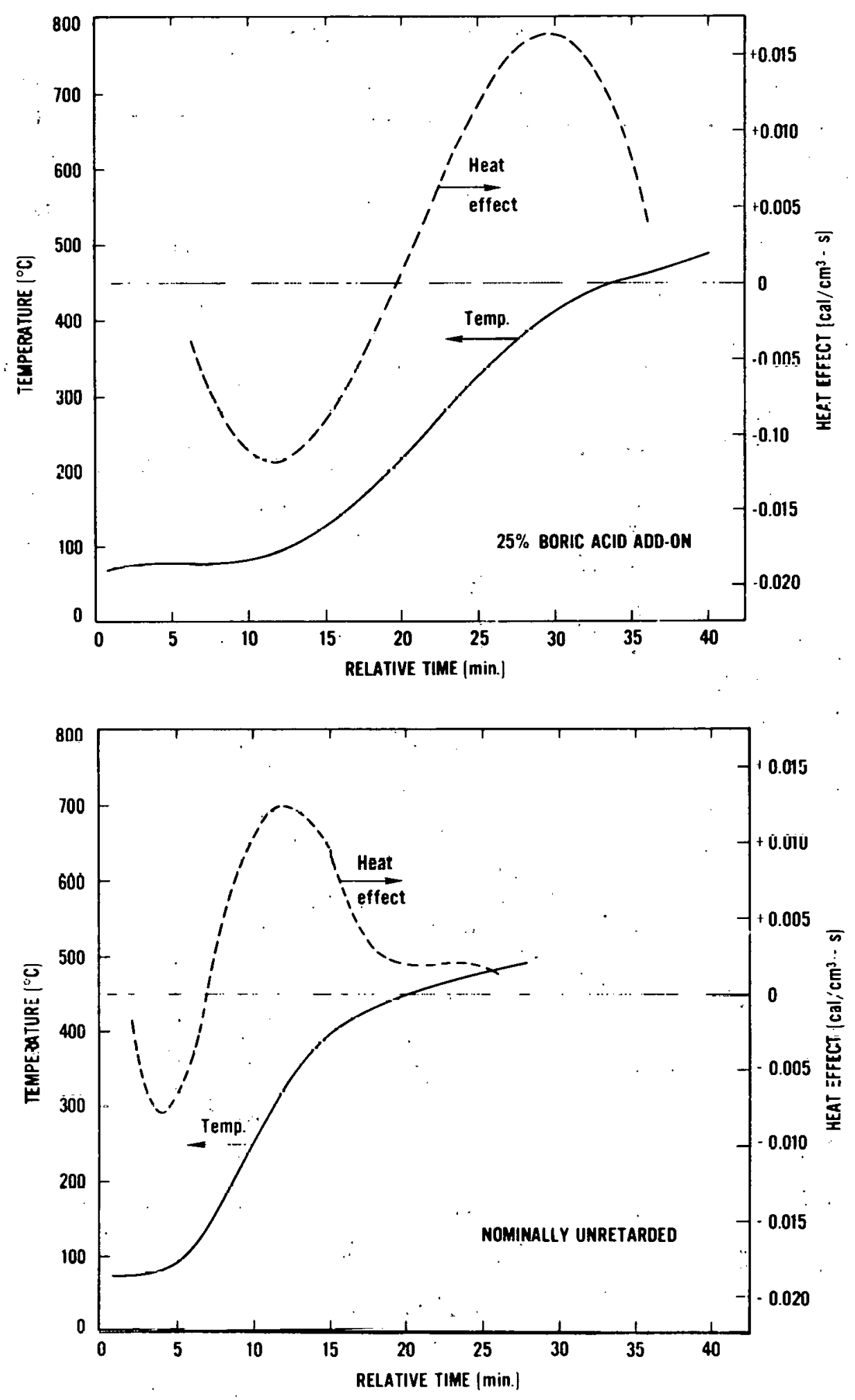

Fig. 7 Heat effects (endothermic and exothermic) inferred from temperature-time trace provided by shallow floating thermocouples. Temperature traces shown here are from the polynomial fits. Heat effects are inferred from these traces via second equation on page 26 . 


\title{
APPENDIX I
}

\section{Cellulosic Insulation Material}

III. Effects of Heat Flow Geometry on Smolder Initiation

\begin{abstract}
The variation with heat flow geometry of minimum heat source temperature which causes smolder initiation in cellulosic insulation has been examined for eight configurations. These configurations. range from a wire-like source, to a flat planar source, to a corner formed by planar sources; they simulate such heat sources as electrical conductors and light fixtures and span the geometry range seen by insulation in practice. The 1gnition temperature for the same $20 \mathrm{~cm}$ deep insulation layer varies from $235^{\circ} \mathrm{C}$ (corner source) to $385^{\circ} \mathrm{C}$ (wire source). Other varlables such as bulk density or the presence of smolder retardants have much less effect on ignition temperature. This behavior is rationalized in an approximate manner by simple heat generation/heat flow arguments; it is predicted semi-quantitatively by a numerical model using reaction kinetics derived from thermal analysis. A smolder ignitability test for cellulosic insulations is suggested that simulates exposures to recessed light fixtures. The data here provide a correlation between results of such a test and ignition temperatures in other configurations.
\end{abstract}

1. Introduction

Cellulosic loose-fili insulation is essentlally re-cycled newsprint, re-ground back to a fibrous mass and intermixed with combustion-retarding additives. The original newsprint is for the most part a mechanically ground wood (balsam fir, black spruce, southern pine, depending on the mill location) shredded to the point of separating the individual wood fibers (Britt, 1964). When this physical form is recovered during insulation manufacture, the result is a high specific surface area, low bulk density material with a high resistance to buoyant air flow. These propertles make this materlal a very good thermal insulator but they also accentuate the tendency of cellulosic materials to undergo self-sustaining heterogeneous oxidation, i.e., smoldering combustion. The combustion-retarding additives (borax for flaming resistance and borlc acid for smolder resistance are most popular) are reasonably successful at suppressing flaming reactions but markedly less so for smoldering reactions. Despite the presence of these additives, when this type of insulation, due to improper installation, is exposed to possible attic heat sources (recessed light fixtures, chimneys, overloaded electrical wires or junction boxes), self-heating can lead to smolder ignition and later to flaming. There have been several residential fires that apparently began in scenarios like this (Zicherman and Fisher, 1978; Gross, 1978). 
The likelihood of heterogeneous self-heating yielding smolder inftiation is greatest when the cellulosic insulation remains in contact with a heat source for an extended period of time (comparable to or greater than the time to yield a steady-state temperature distribution around the source if the insulation was chemically inert; we call this the thermal relaxation time. For source geometries found in attics, typical relaxation times are from two to twelve hours. A heat source that persists for this period will effectively preheat the insulation, making it possible for a lesser self-heating rate to cause ignition.

If the exothermicity (heat release per gram reacted) of the reaction is sufficient, the solid fuel need not be excessively consumed during this heat-up interval and ignition can progress as the heat losses from the reaction zone diminish. There will be some minimum heat source temperature for a given material (dependent on geometric configuration) just sufficient to produce ignition after this thermal relaxation interval; this is the quantity of interest here and is referred to as the minimum ignition temperature borderline.

Problems such as this have been extensively examined (at least for simple geometries) in the context of thermal ignition theory (Gray and Lee, 1967; Merzhanov, 1971). For the present class of problem, this theory reduces to finding the highest heat source temperature for which ignition does not occur. When reactant consumption is negligible; non-ignition results in a steady state where heat. from the source and from the self-heating near the source flows continually outward through the insulation to ambient. Theoretically and experimentally, one looks for the limit on this steady state and Identifies it with the minimum ignition temperature.

In previous work (Rogers and Ohlemilier, 1980), quantitative expresslons were given for the two overall stages of oxidative heat release from a cellulosic insulation*; theșe rate expressions were successfully applied (Ohlemiller and Rogers, 1980a) to the prediction of minimum smolder ignition temperatures for the simplest heat flow geometry (insulation layer on a flat, heated plate). In that work, It was shown that it is the first overall oxidative degradation.stage of the insulation (peaking at approximately $320^{\circ} \mathrm{C}$ in a DSC scan at $5^{\circ} \mathrm{C} / \mathrm{min}$ ) that is responsible for smolder initiation. The thermal ignition model of Bowes et al. (Thomas and Bowes, 1961, Bowes and Townshend, 1962) was used, together with the first stage rate expression, to make a reasonably good estimate of minimum ignition temperature dependency on insulation layer thickness.

Here those results are extended to more complex and realistic insulation/heat source configurations. The variability of minimum ignition temperature with heat sources analogous to attic sources is explored together with the ability of thermal ignition theory to predict this variability. We want to establish the variability of ignition hazard with differing

\footnotetext{
*The kinetic parameters of these are given in the Nomenclature Table; note that the $Z$ values there contain ambient oxygen concentration and bulk fuel density implicitly.
} 
source types and also provide some "calibration" data for a possible test method. In addition, we look briefly at what the theory Implies is the necessary change in oxidation kinetics of the insulation in order to ralse ignition temperatures substantially. Finally, implications for a possible improved smolder ignition test method are examined.

\section{Experimental Ignition Measurements and Observations}

\subsection{Apparatus}

Eight heat source configurations were examined; Figure 1 shows schematic sectional views of them; two were one-dimensional flat plate cases (configuration F: 7 cm insulation layer; configuration G: $5 \mathrm{~cm}$ layer) as in Ohlemiller and Rogers (1980a). The six other heat sources in Figure 1 were tested in an "attic mock-up" so that their thermal environment would resemble the real-world hazard situation; this should facilltate a reasonably quantitative carry over of the present data to such scenarios. The sources are essentially idealized versions of an electrical wire (H), a chimney face (D) and recessed $11 \mathrm{ght} f i x t u r e s$ $(A, B, C, E)$. A schematic top view of the attic mock-up in which they were mounted is shown in Fig. 2. Briefly, this consists of a trough $30.5 \mathrm{~cm}$ wide formed by two 2 by 8 's (pine floor joists; actual dimensions $4.8 \mathrm{~cm}$ thick by $18.3 \mathrm{~cm}$ high). Outside of the trough, on the other side of each $2 \times 8$, is a $7.6 \mathrm{~cm}$ wide $\times 20 \mathrm{~cm}$ deep layer of mineral wool insulation to help simulate a large. insulated attic expanse. The floor of the trough is a $6 \mathrm{~mm}$ thick transite board. The floor is not in direct thermal contact with the bench on which the mock-up sits so that, like an attic floor, it loses heat only by. convection (and radiation) to an open air space below 1t. This attention to the thermal environment of the heat source is made necessary by the time scale of the tests (many hours); the heat source has time to become influenced by these surroundings, especially in all the directions that fall in the plane of Figure 1. Heat flow in the direction perpendiculär to the plane of Figure 1 (toward the 2 by $8^{\prime} \mathrm{s}$ at the sides of the trough) is less important (but still present) for most of the configurations tested since they are designed to be fairly two-dimensional in nature. These sources are, in all cases, at least $25.5 \mathrm{~cm}$ wide and centered laterally in the trough. Under these circumstances; only configuration $B$ in Figure 1 is significantly influenced by conduction of heat in the direction perpendicular to the plane of the figure (ratios of both source dimensions to the depth of the layer are about unity in this case). This was confirmed by probing the steady-state temperature field in the various configurations.

The heat sources themselves are designed to be very uniform in temperature. The planar sources in Figure 1 are made as follows. A long, thin heating element, shaped into a raster-scan-1ike pattern (with less than $2.5 \mathrm{~cm}$ spacing) is sandwiched between two brass plates. The side away from the sample material is covered with $2.5 \mathrm{~cm}$ of ceramic felt insulation. The design provides very good temperature uniformity $\left( \pm 1^{\circ} \mathrm{C}\right.$ except within about $2 \mathrm{~cm}$ of the edges) while st1ll giving rapid heat-up (12-14 minutes required to reach typical set point temperatures). The heat source in configuration $\mathrm{H}$ is a $4.8 \mathrm{~mm}$ diameter copper 
tube that spans the trough and concentrically encloses a heating element. Here, as with the planar sources, the temperature is controlled at the desired value $\left( \pm \leq 1^{\circ} \mathrm{C}\right)$ by a controller with a sensing thermocouple (.020 cm wire) in firm contact near the center of the source (two sources and two controllers in configuration A). Because of an unavoldably large power to mass ratio in configuration $\mathrm{H}$ (only), the temperature oscillated (period about 5 minutes) $\pm 2-3^{\circ} \mathrm{C}$ about the set point. All heat sources were given a thin coating of collotdal graphite paint to provide a reproducible surface.emissivity (radiation into a porous fuel bed can be significant).

In configurations $C$ and $E$, where the planar heat source is elevated above the floor of the trough, the source forms the top of a sheet metal box $(0.08 \mathrm{~cm}$ steel). The box penetrates the floor of the trough and is airtight at and above floor level. It is completely open to the air space below the mock-up but does act as a trap for heated air as noted later.

Additional probes were used in various tests to help assess insulation behavior. Typically these were $0.025 \mathrm{~cm}$ diameter sheath thermocouples (chromel-alumel) inserted parallel to the plane of the heat source. Junctions were placed both about $0.64 \mathrm{~cm}$ away from the source center and about $3.8 \mathrm{~cm}$ away; both were on the line normal to the source plane and passing through the source center. The inner thermocouple(s) helps assess the proximity of a given test condition to the minimum source temperature border for ignition (very near the ignition border, the gradient near the heat source goes to zero or may become negative). The outer thermocouple monitors the gradient away from the source on a larger scale and is a good indicator of the achievement of a non-igniting steady state (at which point the test can be terminated). In addition, in tests with several of the configurations, a long syringe needle ( $1 \mathrm{~mm} O D$ ) was mounted parallel and adjacent to the near-source thermocouple (s). Small ( $1 / 2 \mathrm{cc}$ ) gas samples were pertodically withdrawn (rate $<1 / 2 \mathrm{cc}$ per minute) and analyzed for $\mathrm{CO}, \mathrm{CO}_{2}, \mathrm{O}_{2}$ and $\mathrm{N}_{2}$ by gas chromatography. The progress of oxygen consumption and pre-ignition reactions could be followed in this manner.

The insulation used in most of the tests was a commercial blend containting a proprietary mix of retardants sufficient to permit passage of current insulation smolder and. flaming tests $^{*}$. Unretarded (or nearly unretarded) material from the same manufacturer was used in two tests with configuration D. All material was thoroughly conditioned to a relative humidity of $50 \pm 5 \%$. Prior to testing it was ball-milled as described previously (Ohlemiller and Rogers, 1980a) in order to fluff it and permit bulk densities typical of commercial application.

\footnotetext{
* The CPSC Interim Standards for Cellulose Insulation (Federal Register, July 6, 1979) require a critical radiant flux for sustained surface flaming of at least $0.12 \mathrm{w} / \mathrm{cm}^{2}$; cigarette ignition of an insulation bed of a specific size must produce less than a $15 \%$ weight loss.
} 
The reader should bear in mind that the cellulosic insulation materials currently on the market vary in starting material and retardant blends. The results here apply to only one manufacturers product but they are believed to be approximately valid for many others.

\subsection{Procedure}

The insulation was weighed out in four separate segments, each sufficient to provide $1 / 4$ of the total layer depth $(20.3 \mathrm{~cm}$ in all cases, $1 . e$, the mock-up was always filled to the top). Each segment was carefully distributed to minimize bulk density variations (a potentially significant source of scatter in such tests. even though average bulk density has a fairly weak effect; see below). When the desired bulk density was the nominal value of $4.4 \times 10^{-2} \mathrm{~g} / \mathrm{cm}^{3}$, each layer required minimal compression ( $5 \mathrm{~mm}$ or less) to yield its $1 / 4$ contribution to the total layer depth. When the target bulk denstty was $20 \%$ higher (5.3 $\mathrm{x}$ $10^{-2} \mathrm{~g} / \mathrm{cm}^{3}$ ), significantly greater compression was required.

In no case was the sample volume used sufficient to f1ll the full length of the mock-up $(91 \mathrm{~cm})$; this would have taxed the sample preparation facilities excessively. Instead, only the space around the heat source and out for a distance of at least $15 \mathrm{~cm}$ was occupied by the sample. The remaining space was segmented-off by means of a steel wire screen (16 mesh) and it was packed with mineral wool at a bulk density of approximately $0.10 \mathrm{~g} / \mathrm{cm}^{3}$. Flow tests showed this packing density to provide a reasonable match to the sample in terms of permeability. Handbook values of specific heat and thermal conductivity (Perry, 1950) imply reasonable matches in these properties. In any event, the sample temperature at the interface with mineral wool never exceeded $10-15^{\circ} \mathrm{C}$ above ambient, implying that this material was well away from the more crucial parts of the temperature distribution.

For the two one-dimensional flat plate cases reported below, the apparatus was that used previously (Ohlemiller and Rogers, 1980a). The Insulation bulk density was the same nominal value $a s$ in the other tests but the thinner beds required packing in two layers only.

The tests themselves are necessarily trial and error attempts to locate the lowest source temperature yielding ignition regardless of exposure length. Several tests on surressive samples are thus required to obtain the desired data point. In each test, after packing, the source is brought quickly up to the desired temperature (12-14 minutes) and held there. The thermal relaxation time of the sample is more difficult to analyze than in the one-dimensional case previously treated (Ohlemiller and Rogers, 1980a) because of the rather complex geometries. A range into which the relaxation time should fall can be estimated from the key dimensions of the particular configuration but the range is typically quite wide. We use the simple $1-D$ formula given in the above reference, $1 . e ., t=0.4 l^{2} / \alpha$, where $\ell$ is the pertinent length and $\alpha$ is the thermal diffusivity of the insulation. For example, from the two depths involved in configuration $C$, one estimates a thermal relaxation 
time in the range from 2.2 to 9 hours; actual ignitions occurred in this case after about 3 hours.

The transient behavior of the sample was followed by the thermocouple and, in some cases, the gas sampling probes. The probes themselves.might somewhat alter the local behavior but they could influence only a small fraction of the igniting material; there was no indication that they altered the overall behavior. The use of the probes was purely an optional exercise aimed at a better understanding of the Ignition event. In principle, one could simply walk away from such a test and come back later to learn the result: ignition or no ignition. The probes were consistently useful, however; in indicating when no further waiting was necessary for a non-ignition case. When, in the neighborhood of the heat source, temperature, $\mathrm{CO}$ and $\mathrm{CO}_{2}$ levels peaked and began a slow decline, the danger of ignition was past. A few tests were continued up to 27 hours because there has been some concern that cellulosic ignition is coupled uniquely to char build-up (Schaffer, 1979). In no case did this extended exposure have any noticeable effect or lead to any new exotherm. It should be noted, however, that the present results cannot answer questions about long term changes in ignitability resulting from months or years of exposure to lower temperatures.

The results of a given non-ignition test were used to judge what heat source temperature to use in the next test (with a fresh sample). If the thermocouple(s) near the source peaked within $\pm 2^{\circ} \mathrm{C}$ of the source temperature; the next test temperature was about $5^{\circ} \mathrm{C}$ higher. The goal was to determine the borderline (minimum) ignition temperature to within about $5^{\circ} \mathrm{C}$ for each configuration. Generally, the position of the borderline was confirmed by performing two tests just above it and two just below it. It probably is futile to attempt to pin down the borderline to much hetter than $5^{\circ} \mathrm{r}$ since material and test condition variability cause approximately this much scatter in results.

\subsection{Observed Transient Behavior and Reactant Depletion in Tests}

The qualitative trends noted with the gas sampling and temperature probes near the heat source are similar to those shown previously for the one-dimensional gcometry (Ohlemiller and Rogers, 1980a). For conditions near the ignition borderline, the variations of temperature and oxygen concentration with time are not greatly different for ignition and non-ignition cases until late in the test. For non-ignition very near the borderline, the temperature near the heat source (i.e., usually measured $6 \mathrm{~mm}$ away) gradually rises to $2-3^{\circ} \mathrm{C}$ above the source temperature and then subsides back to a few degrees léss than.the source, eventually approaching a steady state value. For the same case, the $0_{2}$ level drops to some rather large fraction of the ambient level, then slowly rises again as the local temperature decreases slightly. Even in the case of configuration B with a high fuel bed density $\left(5.3 \times 10^{-2} \mathrm{~g} / \mathrm{cm}^{3}\right)$, where one would expect the greatest $0_{2}$ depletion, the $0_{2}$ level stays at or above $80 \%$ of the ambient air level. 
Behavior during a test where the source temperature is just above the borderline for ignition is similar for an extended period of time. However, the near-source temperature will continue rising gradually, typlcally accelerating appreciably when it is about $5^{\circ} \mathrm{C}$ above the source (for deeply imbedded sources such as in $B$, the actual runaway may only be seen in the more distant thermocouple). Only when the rate of temperature rise accelerates does the $\mathrm{O}_{2}$ level near the source drop below about $70 \%$ of the ambient air level: Subsequent spread of the smolder zone is probably $\mathrm{O}_{2}$-limited; it can require up to an additional 3 hours (configuration B) to reach the visible surface of the Insulation bed, where it is apparent as a growing blackened zone that shrinks somewhat.

The effects of oxygen depletion on the ignition event are minimal since the depletion itself is minimal. This is particularly apparent in 1ight of the weak dependency of the ignition reactions on oxygen concentration (0.43 power) (Rogers and Ohlemiller, 1980 ). Consumption during ignition of the reactant for the first overall oxidative degradation stage of the fuel cannot readily be measured directly. An estimate of depletion was made previously (Ohlemiller and Rogers, 1980a) using reaction kinetics derived from thermal analysis. It was shown there that depletion is less with deeper fuel beds such as used here (with their lower Ignition temperatures) but not negligible. One can estimate that solid reactant depletion will slow the ignition reactions by something less than a factor of two; this in turn translates into something less than a $10^{\circ} \mathrm{C}$ increase in ignition temperature. ('ihe actual effect. may be half or less of this upper bound estimate).

Configuration H (hot wire-1ike source) is a definite exception with regard to the magnitude of solid reactant depletion. The ignition temperature (see below) with this small source was so high that there were indications of substantial fuel consimption near the source.

With the exception of configuration $H$, we note that reactant consumption effects are rather smal1. Furthermore, the behavior of a borderline ignition case is quite similar to a borderline non-ignition case untll the former finally runs away. The experimental picture thus reasonably resembles the physical picture implicit in the thermal ignition theory model of Bowes and Townshend (1962). That is, the last non-ignition state (highest source temperature that does not produce an accelerated runaway to ignition) results in a nearly steady-state temperature profile where heat flows from the source (and from exothermic reactions), through the insulation to ambient. It is nearly steady because solid reactant concumption takes substantially longer than does the primary thermal relaxation process due to heat flow from the source. (It is reactant consumption that causes the peaking out and reversal of $\mathrm{O}_{2}$ and temperature trends in the non-ignition cases noted above; this implies that reactant consumption time is not drastically less than the thermal relaxation time.) With these considerations in mind, we adapt the Bowes and Townshend model to the present geometries below. First, however, the measured ignition data will be glven. 


\subsection{Measured Minimum Ignition Temperatures}

The results for eight experimental configurations are summarized in Figure 3. 'l'wo of these are one-dimensional flat plate configurations (two different layer depths) similar to those reported previously (Ohlemiller and Rogers, 1980b). They are included so as to put such results into the context of the present more realistic configurations.

It is apparent that the configurations vary widely in their smolder ignition tendency as measured by minimum ignition temperature; there is a $150^{\circ} \mathrm{C}$ range between the corner (A) and hot wire $(\mathrm{H})$ configurations. As will be seen below, the important factor that varies across this range of configurations, causing their ignition temperatures to differ, is the rate of heat loss and heat generation per unit volume from the hottest layers of insulation. The range covered here probably encompasses most practical ignition hazard situations.

On the basis of relative minimum ignition temperatures it appears that an overheated electrical wire is a substantially lesser smolder ignition hazard than the other larger area sources. (There are, of course, other elements that may affect hazard assessment.) It is probable that the overload needed in a copper conductor to produce the observed ignition temperature would open a properly rated circuit breaker before it could be achieved (Gross, 1978). On the other hand, the work of Yarborough et a1. (1979) and of Gross (1978) clearly demonstrates that recessed light fixtures covered with insulation and containing light bulbs in excess of their rated power can achieve peak temperatures in the range seen for configurations $A$ to $\bar{E}$; some of these cases were found to Ignite.

Yarborough found that the peak temperatures achieved in insulated recessed light fixtures correlated reasonably well with the electrical power per unit ceiling-exposed area. This area on the ceiling side of the fixture is where $85-90 \%$ of the electrical heat is dissipated; only 10-15\% goes through the insulation surrounding the fixture in the attic. This led Yarborough to the reasonable conclusion that increasing the insulation thickness on top of the light fixture would not substantially increase its peak temperature. (The greatest thickness on top of the fixture in those studies was $7.6 \mathrm{~cm}$ ). Even so, the present work predicts an increased hazard from increased thickness; compare configurations $F$ and $\dot{G}$ in Figure 3, for example.

Note that configuration $B$ has a lower ignition temperature than configuration $C$. The source dimensions are the same in both cases; only the insulation depth varies. Configuration $B$ can be viewed in two ways: (1) as a simulation of a recessed light fixture of the same dimensions as $\mathrm{C}$ that is covered on top with twice the thickness of insulation or, (2) as a simulation of a fixture mounted flush on the underside of the attic ceiling. As a simulation of role (1) one finds, as expected, that $B$ has a lower minimum ignition temperature than $C$. The role (2) simulation is deceptive, however. It is wrong to conclude that the results in Fig. 3 imply that the fixture mounted on the underside of the ceiling 
is more dangerous than the same size fixture recessed as in $C$. The fixture on the underside of the celling will dissipate virtually all of its electrical heat to the room below the attic and, being essentially uninsulated, would require much more electrical power input to achieve the minimum ignition temperature shown in Fig. 3. (Note that role (2) also neglects the heat flow resistance of the ceiling itself and, in effect says that the indicated area of the upper surface of the ceiling itself is at the temperature of source B.) One should bear in mind that the electrical power input to an immersed heat source is a separate factor in hazard assessment that could not be included here.

Configuration A is probably a worst case, not likely to be found in practice. It is worth noting, however, that the complex shape of some light fixtures creates concave corners that could increase their hazard somewhat.

\subsection{Bulk Density and Retardant Effects}

These factors were examined only brlefly here to see if their effects were consistent with those seen previously (Ohlemiller and Rogers, 1980a and Ohlemiller and Rogers, 1980b). A bulk density increase of $50 \%$ was previously found to lower the minimum ignition temperature by $10^{\circ} \mathrm{C}$ or less for a $7 \mathrm{~cm}$ layer of the particular insulation used in the one-dimensional flat plate configuration. Here the bulk density was increased by $20 \%\left(\right.$ to $5.3 \times 10^{-2} \mathrm{~g} / \mathrm{cm}^{3}$ ) in configuration D (vertical flat plate heat source) and in configuration B (same heat source flush with bottom floor of mock-up); the effect in both cases was a. lowering of the ignition temperature by $5^{\circ} \mathrm{C}$ or less.

Bulk density. changes affect several parameters in the ignition problem: thermal conductivity of the insulation, bed resistance to air inflow and solid fuel concentration. Changes in thermal conductivity are quite smal1 (Brookhaven National Laboratory, 1978) and are such as to counter the effects of changes in fuel concentration. This last variable is shown by the mode1 helow or that of Bowes and Townshend to have a rather weak effect on ignition temperature. The effect of bulk density on bed flow resistance to alr is large but, as was seen above, oxygen depletion is not a serious problem even in the higher density tests. This type of test is thus fairly insensitive to bulk density variations although caution is needed as noted below. This is reassuring since this material is rather difficult to pack in a highly reproducible fashion.

Unretarded insulation was examined only in two tests with configuration $D$ (vertical flat plate source). The bulk density was $0.042 \mathrm{~g} / \mathrm{cm}^{3}$ so that the actual concentration of solid fuel was somewhat higher here than in the retarded cases (where roughly $25 \%$ of the bulk density is accounted for by the retardants). The results, though sketchy, confirm the rather small change in ignition temperature induced by present-day retardants (Ohlemiller and Rogers, 1980a). Here the unretarded borderline lies only $15-20^{\circ} \mathrm{C}$ below that fur the commercially retarded material as it did in the previous tests. The Implications of this 
for the insulation ignition problem were discussed previously (Ohlemiller and Rogers, 1980a).

\subsection{Material Variability}

Al1 materlal used in these tests was obtained from a single manufacturer and was made on the same day. Nevertheless, when an attempt was made to reproduce the original ignition borderline for configuration B using insulation from a second bag, the new borderline was: found to be reproductbly $10^{\circ} \mathrm{C}$ higher (see Table II below). This prompted a series of further tests to discern if changes in experimental conditions (fume hood cross-flow: rate; mock-up mechanical support, etc.) had caused the change; none of these had any effect. The new bag of insulation was found, however, to have a $30 \%$ higher equilibrium moisture content $(\sim 13 \%$ vs $10 \%)$ and a $15 \%$ lower ash content $\left(1\right.$ hour at $650^{\circ} \mathrm{C} ; 17 \%$, vs $20 \%$ ). ciear 1 y there was a change in retardant mix and possibly loading level; the paper stock may also have varied. The nature of the chemical change has not been identifled but these results provide a measure of variability in these materlals on any given day.

\section{MODELING OF IGNITION BEHAVIOR}

\subsection{Phenomenological Model of Configuration Effects on Ignition}

The above results coupled with our previous work indicate that for cellulosic insulation the heat flow configuration has more impact on smolder Ignition temperature than any other variable. It is instructive to formulate some crude models of the heat flow/heat. generation for a few cases to see why this is so. In a subsequent section we will solve the problem more exactly but the simple heat balance effects that influence ignitinn temperature are somewhat obscured. The goal here is limited to demonstrating that the shifting balance of heat generation rate versus heat loss rate leads quite naturally to an ignition temperature that varies with geometry. 'l'he models posed here for three geometries are intended only to demonstrate the source of this variation; they are not intended as formulae for routine use in calculating ignition temperatures since substantial apprnximatinns are made at certain points. The reader who needs no convincing as to the source of the ignition temperature variability may wish to proceed to the next section.

When ignition does not occur for a given source temperature, it is because the heat from the source and from the reacting insulation near the source is lost to the ambient surroundings. Thus we have in general:

$$
\int_{S_{1}} \dot{q}_{\text {source }} \mathrm{ds}_{1}+\int_{\mathrm{v}} \dot{\mathrm{q}}_{\mathrm{cr}}^{\prime} \mathrm{dV}=\int_{\mathrm{S}_{2}} \dot{\mathrm{q}}_{\text {loss }} \mathrm{ds}_{2}
$$

Here the first integral is the total inflow of heat to the insulation as a result of conduction from the heated source to the cooler elements of adjacent insulation; the second integral sums the heat release contributions from the entire volume of the insulation (only 
that near the heat source is significant; as will be seen); the third integral sums all the losses from the surfaces of the Insulation where 1 is hotter than the adjacent material (ambient surroundings). Because of the Arrhentus temperature dependence of the chemical heat generation term, $\dot{q}_{c r}^{\prime}$, (Rogers and Ohlemiller, 1980) it and its integral are negligible until the heat source temperature approaches the borderline for ignition. As the borderline is approached there is an abrupt change in the relative importance of the two terms on the left hand side of Equation (1); the second term grows and the first shrinks. This latter effect occurs because the reaction, again due to its. Arrhenius temperature dependence, proceeds fastest right where the insulation is hottest, $1 . e$. , at the interface with the heat source. Heat evolution there raises the local temperature in the insulation just enough to drive the temperature gradient at the interface approximately to zero (Bowes and Townshend, 1962) just as the ignition borderline is reached. (This is only locally true for certain geometries; see below). Further increase in the source temperature causes the chemical reaction term to grow so much that the steady state balance of Equation (1) is no 1onger possible and ignition occurs. We will use the idea that, at the borderline, the second and third terms of Equation (1) are essentially in balance; this becomes our criterion for achievement of the minimum ignition temperature. This will be done for three geometries by estimation of the values of these two terms for each case. It will be seen that different geometries change the minimum ignition temperature chiefly because they imply changes in the volume of material generating heat relative to the surface area losing heat.

First consider a one-dimensional flat geometry such as that in configurations $F$ and $G$ Define an effective reaction layer depth, $\ell_{R}$, adjacent to the hot plate as follows

$$
\int_{V} \dot{q}_{c r}^{\prime} d V \equiv \int_{0}^{\ell} Q_{1} z_{1} \exp \left(-\frac{E_{1}}{R T}\right) d x=\ell_{R} Q_{1} z_{1} \exp \left(-\frac{E_{1}}{R^{2} \cdot p}\right)
$$

Unit area of the hot plate is implicit here so the volumetric integration becomes an integration over the insulation layer depth, $\ell$ : Subscript 1 means that we expect the first overall oxidation stage of the cellulosic Insulation (recall that two overall stages were found, as described earlier) to be responsible for ignition in this case; this was shown to be true previously (Ohlemiller and Rogers, 1980a). The kinetic parameters $\left(Q_{1}\right.$ the heat release, $Z_{1}$ the pre-exponential factor and $E_{1}$, the effective activation energy) obtained from thermal analysis were shown in this reference to glve good estimates of ignition temperatures when used in the Bowes and Townshend model. Here we are constructing a more approximate model to estimate the effect of changing geometry. We estimate the value of the middle integral above by inserting the Iinear, steady state temperature profile for the non-reactive case (Carslaw and Jaeger, 1959a). In view of the above discussion about the gradient at the interface with the source, this is clearly approximate; it works best a few degrees below the ignition border rather. than at 1t. When this is done, we can solve for $\ell_{R}$ after performing the integration (the Frank-Kamenetskil approximation to the exponential is uocd as in Bowes and Townshend, 1962). 


$$
l_{R}=\left(R T_{p}^{2} / b E_{1}\right)
$$

where

$$
b=\left(T_{p}-T_{A}\right)(h / \lambda)\left(\frac{i}{1+(h \ell / \lambda)}\right)
$$

is the negative of the slope of the linear temperature profile. The other symbols can be found in the Nomenclature Table. When evaluated, $\ell_{R}$, which measures the reacting volume, is found to be a small fraction of the layer depth (see below).

Now it is convenient to focus attention on this reaction layer and apply Equation (1) to it rather than to the whole insulation bed. The same statements made above about the balance of terms at the ignition border apply here as well. Therefore we still estimate the ignition temperature at the border by equating the chemical heat generation in the reaction layer to the rate of heat loss from the layer. Thus, for this one-dimensional geometry we get

$$
Q_{1} z_{1} l_{R} \exp \left(-E_{1} / R T_{p}\right)=\lambda\left(\frac{T_{P}-T_{A}}{\ell}\right)
$$

Here in estimating the heat loss from the reaction zone, we used ambient temperature $T_{A}$ rather than the more accurate outer surface temperature avallable from the inert solution; for the present purpose of comparing geometric effects under one set of conditions this is adequate. Equation (5) can be solved, by trial and error for example, to obtain the predicted border ignition temperature $T_{p}$ for the one-dimensional flat plate case; we report the results below.

Consider next the case of a hot wire at mid-depth in an insulation layer (configuration $\mathrm{H}$ ). Here we do not have an exact temperature distribution for the inert case. For present purposes, it is sufficient to use the solution for a concentric cylindrical bed of insulation surrounding the wire (Carslaw and Jaeger, 1959b); we take the radius of the cylinder as the half-depth of the bed. Use of the radial geometry means we can only roughly approximate $_{3}$ configuration $\mathrm{H}$; ail that is needed here is an approximation to the reacting volume very near the wire, obtained by iinearizing the temperature distribution there. (Alternatively, we could treat the concentric cylindrical bed instead, as an example of an extreme convex heat source geometry; the numerical estimates would be very.similar.) The linearized profile is

$$
T(r)=T_{p}-\left[\frac{\left(h \ell_{2} / \lambda\right)\left(T_{p}-T_{A}\right)}{1+\left(h \ell_{2} / \lambda\right) \ln \left(l_{2} / \ell_{S}\right)}\right]\left(r / l_{S}-1\right)
$$

The slope here is about an order of magnitude steeper than in the one-dimensional flat case due to the higher surface to volume ratio here; this implies a substantially thinner reaction zone. Furthermore, the radial geometry near the source Implies a higher heat loss rate per unit of reaction volume. These two changes will be found to imply a substantially higher 
ignition temperature than in the flat plate case. Proceeding in a manner exactly analogous to the one-dimensional case, we find

$$
\ell_{\mathrm{R}}^{\prime}=\ell_{S}\left\{1+\frac{2}{\left[\mathrm{~b}^{\prime}\left(E / R T_{\mathrm{p}}^{2}\right)\right]^{2}}\left[1+\mathrm{b}^{\prime}\left(E / \mathrm{RT}_{\mathrm{p}}^{2}\right)\right]\right\}^{1 / 2}
$$

where $b^{\prime}=\left[\frac{\left(h \ell_{2} / \lambda\right)\left(T_{p}-T_{A}\right)}{1+\left(h \ell_{2} / \lambda\right) \ln \left(\ell_{2} / \ell_{S}\right)}\right]$

and the ignition condition, equating heat produced and lost in the thin reaction zone around the wire is:

$$
(1 / 2) Q Z\left(\ell_{R}^{\prime 2}-\ell_{S}^{2}\right) \exp \left(-E / R_{p}\right)=\lambda\left(2 \pi \ell_{R}^{\prime}\right)\left(\frac{T_{p}-T_{A}}{.75 \ell}\right)
$$

Here $\ell_{R}^{\prime}$ is the outer radius of the cylindrical reaction zone so that the actual reaction layer is $\left(\ell_{R}^{\prime}-\ell_{S}\right) ; \ell_{S}$ is the radius of the hot wire. The heat loss estimate on the right is rough; the denominator is the mean of the two pertinent length scales $\ell$ and $\ell_{2}$. Again, the predicted minimum ignition temperature can be found by solving for $T_{p}$. This time we have not specified which reaction stage is pertinent since we will look at both below.

Finally, consider the concave corner, configuration A. Here there is a new complication. The reaction zone does not extend equally over the interface between the bed and the source. The near-corner region is concave and has a higher surface to volume ratio, now working oppositely to the hot wiresituation, so that there is a favored zone here where reaction occurs most extensively. It is this zone to which we want to apply our ignition criterion. By means of flux plotting (Eckert and Drake, 1972) or by use of the exact numerical solutions described below, one can show that the igniting volume is nearly isothermal near the border and is roughly triangular (with the converging hot walls forming two sides of the triangle). The isothermal lines in the corner are roughly twice as far from the nearest point on the heat source as they are when one considers the same isotherm well away from the corner region. In the latter case, the isotherms approach the spacing (from the source or from each other) they would have in the planar 1-D case. The reaction volume of interest here is thus roughly given by the following

$$
V \simeq(1 / 2)\left(4 \sqrt{2} \ell_{R}\right)\left(2 \sqrt{2} \ell_{R}\right)=8 \ell_{R}^{2}
$$

where $\ell_{R}$ is the one-dimensional reaction layer thickness as expressed by Equations (3) and (4); the actual value of $\ell_{R}$ is greater here because the pertinent layer depth in Equation (4) 1s greater.

Estimating the heat loss rate from this volume is equally difficult in this case. $\Lambda$ gain one must resort to flux plotting or to the exact numerical solution to make a reasonable estimate. The final result, analogous to Equation (5) or (9), 1s: 


$$
8 l_{R}^{2} Q_{1} z_{1} \exp \left(-E_{1} / R T_{p}\right)=\lambda\left(4 \sqrt{2} \cdot l_{R}\right) \frac{\left(T_{p}-T_{A}\right)}{\left(a_{1}^{2}+a_{2}^{2}\right)^{1 / 2}}
$$

Here $a_{1}$ and $a_{2}$ are the lengths of the heated walls and we have found that the effective length for conductive loss from the favored reaction volume is approximately equal in length to a diagonal joining the ends of these walls. (The heat loss flux vector is roughly oriented out from the corner along the opposite diagonal.) Equations (11) and (5) are similar; comparing them, one finds that the igniting volume suffers a substantially lesser loss rate in the case of the corner configuration than in the case of the flat plate source.

When numbers are put into the above equations, the results in Table I are obtalned.

Tab1e I Estimated Dependence of Minimum.Ignition Temperature on Configuration

\section{Configuration}

F: 1-D flat plate, $7 \mathrm{~cm}$ insul. lst stage kinetics

A: corner w. $20 \mathrm{~cm}$ insul. 1st stage kinetics

$\mathrm{H}: 0.24 \mathrm{~cm}$ radius wire, $20 \mathrm{~cm}$ insul. lst stage kinetics

$\mathrm{H}: 0.24 \mathrm{~cm}$ radius wire, $20 \mathrm{~cm}$ insul. 2nd stage kinetics
Reaction Layer Thickness $(\mathrm{cm})$

0.4

1.2

0.05

0.05
Ignition Temperature Est imate $\left({ }^{\circ} \mathrm{C}\right)$

350 480

The approximations are least in the one-dimenstonal flat plate case and here our estimate applied to this specific case is only $7^{\circ} \mathrm{C}$ higher than the experimental result in Figure 3. The approximations are clearly less good in the other cases but we have in fact captured the trend of change with configuration reasonably well. The goal here was not to make quantitative predictions of ignition behavior but rather to illustrate that the variable ignition temperature behavior can be rationalized on the basis of simple heat balance arguments. We have demonstrated that geometry has a big impact on reaction volume (and thus total heat generation rate at a given temperature) and on heat losses from that volume; these differences are made up by changes in heat source temperature that finally destroy the heat balance and cause ignition.

Configuration $\mathrm{H}$ was examined for both stages of decomposition because the ignition temperature implied by the first stage is so high. It was shown previously (Ohlemiller and Rogers, 1980a) that in circumstances where the ignition temperature is high there can be extensive consumption of the first stage reactant in the early transient part of an ignition test. Here the ignition temperature is so high that there could be total consumption of first stage reactant within roughly the thickness shown in Table I during the transient 
(without causing ignition). Then as the transient gradient near the source diminishes and conditions for ignition become more favorable, ignition will have to be as a result of either further stage one reaction outside the consumed annular region or stage two reactions within the annular region (or both). Neither case is well-described by the present models but the results in Table I do imply minimal assistance from reaction stage 2 (char oxidation); comparing the second stage prediction with the actual value in Figure 3 shows that the former is $100^{\circ} \mathrm{C}$ higher. It is thus more likely that the first stage produces ignition but requires: a higher source temperature to overcome the insulating effect of the depleted layer. The: results below provide some further support for this.

\subsection{Numerical Model of Ignition Behavior}

The above arguments are informative but too imprecise for further purposes here. We want to make a more quantitative test of the ability of thermal ignition theory to predict the results in Figure 2 and also to put the theory to use in suggesting test configurations.

The model here simply generalizes that of Bowes and Townshend to the various two-dimensional configurations of Figure 1. Thus we solve the steady-state two-dimensional heat conduction problem incorporating the possibility of a zeroth order, Arrhenius-type exothermic chemical reaction within the insulation. We have noted above that oxygen depletion is minimal and can be neglected without significant error. Except in the case of configuration $\mathrm{H}$, fuel depletion is also small. Our previous results (Ohlemiller and Rogers, 1980a) Imply that for configurations A to G, reactant depletion at most results in an upward shift of ignition temperature by 5 to $10^{\circ} \mathrm{C}$ and probably less (shift is greatest for highest ignition temperature). As in the experiments, we are interested in finding the upper limit on on the steady-state; this is the minimum ignition border.

The model here includes only conductive heat transfer through the insulation material itself. It was noted briefly in a previous section that radiation can become a significant heat transfer mode in porous materials and it is not zero here. However, an estimate of the infrared radiative path-length for this particular material (few tenths of a millimeter, ref. 27) implies its inclusion would be a minor correction here. Buoyant convection of air through the permeable fuel bed is more significant in some cases. One can estimate the order of magnitude of the flow velocity from a force balance of drag versus buoyancy (ref. 16); the result is a few tenths of a millimeter per second. This is liable to be approached only in configurations with extended hot vertical surfaces such as $A$ and $D$. In such a case, the convective flux near the source can amount to $30 \%$ of the conductive flux from the source but they are at $90^{\circ}$ with respect to each other. In view of the considerable complexity that inclusion of internal buoyant convection would entail, coupled with the results below that indicate changes in effective thermal conductivity have a very minor effect on ignition temperature, there is little incentive to include this convective heat transfer mode. 
In contrast to the rough model of the previous section, here we treat the entire Insulation bed, allowing the possibility of reaction throughout; the boundary conditions dictate the locus and extent of reaction. The governing equation is thus:

$$
\frac{\partial^{2} T}{\partial x^{2}}+\frac{\partial^{2} T}{\partial y^{2}}=-\left(\frac{Q Z}{\lambda}\right) \exp (-E / R T)
$$

The reaction parameters $Q, Z$, and $E$ are derived from thermal analysis as indicated above. The parameter $\mathrm{Z}$ is a composite number containing oxygen and fuel concentrations (bulk density), both of which are taken here as constant. The thermal conductivity, $\lambda$, is constant here. This parameter was initially taken as temperature-dependent using the data of Tye (1974). However, this proved to have 1ittle effect $\left(<3^{\circ} \mathrm{C}\right)$ on the minimum Ignition border and was costly in terms of computer memory; a11 cases reported here are for $\lambda$ constant. Solutions to this steady-state equation are sought subject to the types of boundary conditions implicit in the various configurations of Figure 1. Thus, in general, there can be up to six sides on the domain of interest. For example, configurations $C$ and $E$ are treated by solving one symmetrical half of the domaln, splitting it along the mid-line of the heat source; the half-domain then has six sides with two due to the indentation into the fuel bed by the heat source. Each side, or portion of a side, is subject to one of the following types of conditions:

$$
\mathrm{T} \equiv \mathrm{T}_{\mathrm{p}}=\text { constant }
$$

or

$$
-\lambda \frac{\partial T}{\partial \mathbf{x}}=h_{E F F}\left(T-T_{\Lambda}\right)
$$

Here $h_{E F F}$ can be zero if the border in question is adiabatic (such as the midline just mentioned); it can be due to the usual convective heat transfer boundary layer for a surface with the appropriate orientation. Finally, in the case of a surface corresponding to the bottom of the attic mock-up, it can be the series equivalent due to the transite board and the convective boundary layer below it.

The assignment of the appropriate boundary condition to a border segment is, for the most part, obvious from Figure 1 with two exceptions. Since the domain of solution had to be truncated at a finite insulation bed length, some compromise was necessary, just as in the experiments. The typical bed length used was $40 \mathrm{~cm}$ and an adiabatic boundary condition was imposed at the cold end. With this length, this condition, which is a simplification, has little effect. The other non-obvious boundary condition is pertinent to configurations $C$ and $E$ where one part of the indented boundary corresponds to the surface of the sheet metal box holding the heat source above the floor of the mock-up at mid-bed depth. During the experiments with these configurations, measurements were made of the temperature of the air trapped within the sheet metal box; a mean value of $147^{\circ} \mathrm{C}$ was used as the ambient temperature together with Equation (14) for this boundary. 
The derivatives on the left side of Equation (12) were approximated by central differences; the exponential term on the right side was quasi-linearized to facilitate solution. The iterative process that quasi-1inearization implies was combined with the iteration inherent in the solution algorithms. Because we are looking for an inherent stability limit on the solution of Equation (12) and this could be confused with numerical instabilities, two separate solution algorithms were employed. A11 of the cases were solved using successive overrelaxation, called SOR (Ames, 1965); a few cases were also solved as a check using an alternating direction implicit method, called ADI (Carnahan, et al., 1969).

The SOR program was first tested against an analytical solution derived.for a chemically inert case similax to (though somewhat less complex than) configuration A. This defined the iteration convergence tolerance necessary to assure temperature distributions within $1^{\circ} \mathrm{C}$ or less of the exact solution. The program was then checked against the model of Bowes and Townshend as to its predictions of the minimum Ignition border for one-dimensional flat plate configurations (e.g., G and F in Figure 2). The SOR program gave results 2 or $3^{\circ} \mathrm{C}$ higher, depending on layer thickness; recall that the present solution does not use the Frank-Kamenetskil approximation to the Arrhenius factor whereas Bowes and Townshend did.

An ADI solution method is generally considered to be faster and more efficlent than the SOR method (McDonald, 1979). For the rather unique requirements of the present problem, this was not found to be the case. Here we are interested in solutions very near where the reaction term is changing rapidly and becoming dominant. This forced the use of large values of the ADI iteration parameter, corresponding to small values of a pseudo-time step, to avoid numerical instability. The ADI method was significantly more difficult and expensive to use in this case. It was used only to check the borderline for conflgurations $\mathrm{E}, \mathrm{H} \mathrm{and} \mathrm{a} 10 \mathrm{~cm}$ analog of configuration $F$. The results were the same as with the SOR method except for an analog to configuration $\mathrm{H}$ where $\mathrm{ADI}$ gave a result $2-3^{\circ} \mathrm{C}$ higher; this latter configuration posed special problems as discussed below. It is interesting to note that this method, which essentially integrates the time dependent problem, does give virtually the same ignition border as that found from the upper limit on the steady state solution.

An overall energy balance check was made on each solution and typically was satisfied to $10 \%$ or better. This could have been improved by means of smaller space step sizes or further iterations but this was found to be unnecessary; highly accurate temperature distributions were not the objective, rather the ignition borderline was the goal and it was not significantly affected by this level of solution inaccuracy.

It is interesting to note that the numerical problem was rather forgiving with regard to space step size. The reaction layer thicknesses in Table I somewhat underestimate the scale of the extended reaction zone but they are indicative of its small magnitude. The step sizes used typically only provided a few points across the width of the reaction zone. Nevertheless, the minimum ignition border shifts only $1-2^{\circ} \mathrm{C}$ when the step size is halved. 


\subsection{Comparison of Numerical Mode1 with Experiment}

The temperature profiles for the non-igniting. cases are generally consistent with what one would expect from the preceding arguments about heat flow and heat generation. Heat generation increases rapidly as one approaches the ignition border and is strongly sensitive to small changes in the local temperature. In a case such as configuration $F$ or $G$, heat evolution occurs in a layer very near the source that extends equally in the lateral direction; in cases $B, C, E$ and $D$, it is concentrated near the center of the source because of the lateral decrease in temperature near the source edges. As expected, in configuration A, heat generation is concentrated in the hot corner.

Here we are interested not so much 1 n the temperature profiles as in the upper 1 imit soluetons to tquation (12), their variation with configuration and how that variation compares with that seen experimentally. The results are shown in Table II. (Numerıcal values of módel päramètés used can be tound in the Nomenclature.Table.) Ëxcept as noted for configuration $\mathrm{H}$, first stage kinetlc parameters were used in the model calculations.

Table II

Comparison of Numerical Model and Experimental Results for Minimum Ignition Temperature

\section{Configuration}

A: $90^{\circ}$ corner $w$. two plates

B : $20 \mathrm{~cm}$ plate, $20 \mathrm{~cm}$ deep

C: $20 \mathrm{~cm}$ plate, $10 \mathrm{~cm}$ deep

D: $20 \mathrm{~cm}$ plate, vertical

E: $10 \mathrm{~cm}$ plate, $10 \mathrm{~cm}$ deep

F: 1-D plate, $7 \mathrm{~cm}$ layer

G: 1-D plate, $5 \mathrm{~cm}$ layer

$\mathrm{H}: 0.48 \mathrm{~cm} \mathrm{dia.} \mathrm{wire,} \mathrm{mid-depth}$

$\begin{array}{cc}\mathrm{T}_{\text {MIN }}\left({ }^{\circ} \mathrm{C}\right), \text { Expt. } \\ 234-235 & 243 \\ \begin{array}{l}255-256 \\ (266) *\end{array} & 265 \\ 272 & 272 \\ 276-277 & 269 \\ 282 & 284 \\ 285 & 284 \\ 298-301 & 297 \\ 380-385 & \left(\begin{array}{c}320 \\ 435\end{array}\right) \star \star\end{array}$

"due to material variability; see text. $\star *$ upper value for first stage kinetic parameters, lower value for second stage; both are somewhat different heat source than in expt; see text.

In general, the ability of the model to account for both the magnitude and the variation of the minimum ignition temperature is quite good. This is a confirmation of the utility of a thermal ignition theory model and of kinetic data derived from thermal. analysis. The exact quantitative agreement for certain cases must be viewed as somewhat fortuitous, a consequence of mutual cancellation of small errors. In view of several approximations--neglect 
of solid fuel consumption, constant thermal properties, the less than perfect match between the kinetic rate law and the thermal analysis data-one should not really expect less than a $5-10^{\circ} \mathrm{C}$ differential between model and experiment.

Configuration $\mathrm{H}$ which mimics an overloaded electrical conductor, clearly is not as well modeled as the other cases. The agreement is poor for at least two basic reasons. First, the actual configuration used in the model has a different geometry than the hot wire. A small round source that produces very high temperature gradients is not easily handled without refinements to the present computer program which has only fixed, equal space step sizes. Since this is a lower hazard configuration, no attempt was made to model it exactly. To get reasonably small space steps, the model focuses on one quarter of the insulation bed as representative, ignoring the differences in heat loss between top and bottom fuel bed surfaces. The model heat source is at one corner of the quarter and is two perpendicular $0.40 \mathrm{~cm}$ segments at fixed temperature enveloping the corner. The source is thus convex rather than concave (the latter posed numerical stability problems) and is significantly larger than the experimental source; this lowers the minimum ignition temperature for either set of reaction kinetics. The $0.2 \mathrm{~cm}$ space step used is comparable to the reaction layer depth; this very poor resolution probably accounts for the somewhat differing predictions of the two solution algorithms.

The second reason for the discrepancy between model and experiment was mentioned previously: the experiment probably involves extensive or total first reactant consumption in the layer next to the source. The results in Table II relnforce the previous indication that, when ignition does occur experimentally, it is due to further first reactant exothermicity rather than to the oxidation of the second reactant (char); as before, the prediction based on second stage kinetics is quite a bit higher than the experimental value.

\subsection{Some Parameter Effects in the Numerical Model}

In our previous work (Ohlemiller and Rogers, 1980a) we noted that the ignition temperature is rather insensitive to the thermal and physical properties of the insulation. This is because these factors, when varied in the rather small realistic range, tend to have roughly linear effects on the heat flow balance that determines ignition; the exponential Arrhenius factor requires very little temperature change to compensate for such balance shifts.

In the model, as in the experiments, the effect of insulation bulk density is minimal (recall that the parameter $Z$ in Equation (12) is proportional to bulk density). In experiments with configurations $\mathrm{B}$ and $\mathrm{D}$, a $20 \%$ increase in bulk density caused less than a $5^{\circ} \mathrm{C}$ decrease in minimum ignition temperature. The model predicts a $3^{\circ} \mathrm{C}$ decrease with configuration $D$ and $a 2^{\circ} \mathrm{C}$ decrease with configuration $B$, 
Ambient temperature ( $1 . e$. , of the surroundings and of the insulation far from the heat source) is again predicted to be a variable of secondary importance. A change from $20^{\circ} \mathrm{C}$ to $80^{\circ} \mathrm{C}$ with configuration A decreases the predicted minimum ignition temperature only about $2^{\circ} \mathrm{C}$. There is no experimental data for comparison. Yarborough (1979) measured a substantially larger effect of ambient temperature on the maximum temperature achieved in recessed light fixtures; this, however, was observed in non-igniting conditions where rapid compensation by the Arrhenius factor did not come into play.

The predicted effect of retardant removal can be examined as was done previously for one-dimensional configurations (Ohlemiller and Rogers, 1980a); reaction kinetic parameters were determined from thermal analysis by the same techniques (Ohlemiller and Rogers, 1980b). The model predicts that for configuration $D$, the unretarded insulation will have a minimum ignition temperature about $14^{\circ} \mathrm{C}$ lower than the retarded case $\left(255^{\circ} \mathrm{C}\right.$ vs. $\left.269^{\circ} \mathrm{C}\right)$. The experiments for this configuration with no retardant (11mited in number) gave a decrease of about $15-20^{\circ} \mathrm{C}\left(255-260^{\circ} \mathrm{C}\right.$ vs. $\left.276^{\circ} \mathrm{C}\right)$. As with the one-dimensional cases previously studied, model and experiment agree that the smolder retardants here are not very effective in improving smolder ignition resistance.

\subsection{Implications for Needed Retardant Effectiveness}

In view of the rather weak effect of these retardants, it is of interest to ask just how much the exothermic behavior of the insulation must be diminished in order to make it safely resistant to smolder initiation under typical exposure conditions. This is really a two-part question. One must first estimate roughly how much the ignition temperature has to be raised above temperatures realized in practice in order to preclude nearly all insulation ignitions. Secondly, one must determine how much the chemical parameters of the insulation have to be changed in order to raise the ignition temperature this much.

If one assumes that recessed light fixture ignitions comprise the bulk of the smolder initiation hazard, the data of Yarborough et al. (1979), combined with the present results, suggest that the overlap in minimum smolder ignition temperatures and achievable maximum temperatures in recessed 1 ight fixtures is $50^{\circ} \mathrm{C}$ or less. Then an approximate answer to the first part of the hazard reduction problem is that the minimum ignition temperature of the insulation needs to be raised by $50^{\circ} \mathrm{C}$. (Again, this does not address the effects of 10 g term exposure to elevated temperatures.)

In prevlous work (Rogers and Ohlemiller, 1980a), it was shown that boric acid, the most effective cellulosic smolder inhibitor avallable, acts rather weakly on the first overall oxidation stage and does not change its effective activation energy. Here we therefore hold activation energy constant and ask what reduction in pre-exponential factor (Q.Z in Equation (12)) is needed to obtain the desired $50^{\circ} \mathrm{C}$ increase in minimum ignition temperature. The answer depends somewhat on configuration. For configuration F (one-dimensional flat 
source, $7 \mathrm{~cm}$ insulation layer), the product $Q \cdot Z$ must be reduced by a factor of 18 ; for configuration A $\left(90^{\circ}\right.$ corner source immersed in $20 \mathrm{~cm}$ layer of Insulation), the product must be reduced by a factor of 25. These are drastic changes; boric acid achieves only about a factor of 2 or 3 reduction at practical loading levels (10-15\% add-on by wgt.). The $50^{\circ} \mathrm{C}$ increase appears to cali for virtual suppression of exothermicity from the insulation up to $300^{\circ} \mathrm{C}$ or more (as measured by DSC at $1-5^{\circ} \mathrm{C} / \mathrm{min}$ ). In short, this is not a goal that appears achievable in the near future.

The nature of the exothermic reactions responsible for this heat release is unknown. It is not even known which component(s) of this wood product--cellulose, hemi-celluloses, lignin--are chiefly responsible. Shafizadeh (1979) has studied the low temperature oxidation of cellulose. There have been numerous other studies of wood component behavior (Beall and Eickner, 1970). The fact which emerges most clearly is that such studies must be ultimately done on the insulation itself; its complex history as re-cycled newsprint implies contamination that could substantially affect its behavior.

\subsection{Implications for Smoldering Ignition Test Methods}

Some general points should be emphasized first. It should be clear from this work and the work of many others (see, e.g., Gray and Lee, 1967; Merzhanov and Averson, 1971) that there is no unique ignition temperature characteristic of a given insulation material. Ignition results from an imbalance of heat generation and heat losses so the temperature at which it occurs depends on all factors affecting these processes. Another point. worth noting is that there is no indication in any work to date that a cellulosic insulation has been made smolder proof; it can only be made more resistant to smolder as measured by various tests. As the test becomes more severe, a previously non-igniting material will ignite.

Under these circumstances, the safest way to assess an insulation's smolder potential in application is to subject it to the heat sources and conditions it will see in 1 ts normal end use. This has been done to a Iimited extent (Yarborough et al., 1979; Gross, 1978) but it clearly is not practicable for production line testing; the source variations are too. numerous and the tests can take 1.2 hours or more. Small-scale testing is unavoidable. In addition to improved convenience, such tests should provide conditions that are pertinent to the real hazard situation and, if possible, are simple enough to be quantitatively analyzed. Exiating or suggested smolier ignition test methods include the use of such heat sources as a cigarette (Gross, 1978), a $0.95 \mathrm{~cm}$ d1a. electrical cartildge heater (Day et al., 1979) and a smoldering bed of unretarded cellulosic insulation (Issen, 1980). These all offer the advantages of simplicity and speed but each has certain shortcomings as well. A cigarette as a heat source is deceptively simple in appearance but is actually quite complex (Summerfield et a1., 1978); it does not resemble sources typically encountered in practice and its behavior could be modified by additives in the insulation under test. There are 
some data indicating a partial correlation between cigarette tests and recessed light fixture tests (Gross, 1978) but it is impossible to know how general this may be since the cigarette test is too complex for detalled analysis.

The electrical cartridge heater used by Day et al. Is a simpler and more invariant heat source than a cigarette. However, it is a small source; the present results indicate that such small sources must be raised to higher temperatures than occur with recessed 1 ight fixtures. By getting away from the appropriate temperature range, one always runs the risk that the relative ignitability of two materials will change (Bowes and Townshend, 1962). Furthermore, the mode of usage suggested by Day et al. is dynamic in nature rather than static (limit on steady state); one measures an ignition delay time as an ignitability ranking paramecer. In view of these tacts, the test as proposed seems more sulted to measuring insulation ignition resistance to localized transient heat sources such as a short clrculeling electrical conductor.

The use of a smoldering mass of unretarded insulation as an "ignition" source (Issen, 1980) is, in a sense, a modification of the cigarette test in which the smoldering heat source has been enlarged. There are again some data showing a partial correlation between this test and recessed light fixture tests; agän the same difficulty pertains in generalizing the results due to the complexity of the test phenomena. This test appears to be more an examination of continued propagation than of ignition.

The present work can be applied to the design of a test procedure which sacrifices some convenience and simplicity but gains comparability with the recessed light fixture hazard. We have two conflicting design goạls; (1) short test time; (2) Ignition temperatures in the same range as with immersed light fixtures: The first calls for a thin insulation layer and the second for a thick layer. It was noted previously that test time with a one-dimensional flat insulation layer is approximately given by $\left(0.4 \ell^{2} / \alpha\right)$, where $\ell$ is the layer thickness and $\alpha$ is its thermal diffusivity. In a test, if ignition is not occurring by this time, one can stop waiting since the layer 1.s as pre-heated as it witl get. (Any extended heat-up time for the source is essentially additive.) Since this implies that test time increases rapidly with layer thickness, we are forced to consider thin layers. A layer of the order of $7 \mathrm{~cm}$ or more is desirable to assure reproducibility in packing and permeability characteristics; thinner layers may have increasing problems in this respect. The preceding expression, $\left(0.4 \ell^{2} / \alpha\right)$ evaluated using thermal conductivity data of Tye (1974) and representative numbers for density and heat capacity, gives a maximum test time of about one hour for a $7 \mathrm{~cm}$ layer. On this basis it appears undesirable to go any thicker. However, Figure 2 indicates that, even at $7 \mathrm{~cm}$, a one-dimensional layer has a minimum ignition temperature of $285^{\circ} \mathrm{C}$. Inspection of the results of Yarborough et al. (1979) implies that the ignition problem with assorted light fixtures begins at about $240-250^{\circ} \mathrm{C}$; thus we want a test that places the minimum ignition border of a nominal commercial material in this range. This can be achieved without increasing the layer thickness or test time by changing 
from a flat plate heat source to one that is more "concave," as in configuration A. For example, the present model indicates that the material used in these tests would ignite at $257^{\circ} \mathrm{C}$ if placed in a two-dimensional "trough" $15 \mathrm{~cm}$ wide and $71 / 2 \mathrm{~cm}$ deep with bottom and sides held at this temperature. A square or circular container with the same dimensions and heating would give a lower ignition temperature. This could be adjusted further downard by decreasing the width somewhat and the maximum test time would remain about one hour. Thus, by manipulation of the heat source geometry, the minimum ignition temperature for this nominal material can be brought down to $240-250^{\circ} \mathrm{C}$.

In view of the variability of attic heat sources and the inevitable small scatter $\left(\leq 5^{\circ} \mathrm{C}\right)$ in test reșults of the present type, such a test would best be used to establish performance classes corresponding to some range of ignition temperatures. For example, the data of Yarborough suggest that recessed light fixture ignitions occur in the range from $225^{\circ} \mathrm{C}$ to $275^{\circ} \mathrm{C}$; this range could be broken into a series of performance classes having ignition temperature ranges from 15 to $20^{\circ} \mathrm{C}$. These borders and the suggested ignition temperature goal in the heat source design are based on the limited data presently available; more work with a greater variety of real heat sources and commercial insulations is needed before they could be firmly established.

With a test such as this, the performance class of a new material could be established in a short time by using four identical heat sources set at the lower temperature limit of each of the above classes. One merely looks for ignition or non-ignition in each case. If a material falls near a borderline, as indicated by the fact that ignition requires a large fraction of the one hour test time, the test at that temperature should be repeated. Routine production checks would require only the checking of the lower temperature limit of the performance class.

In a go/no-go test such as this, one should realize that variation in a parameter such as bulk density can cause a borderline material to go from ignition to no ignition or vice versa. This is in spite of the fact that bulk density was shown above to have only a weak effect on ignition temperature. This is inherent in any go/no-go test and implies a need for care in preparation.

This test has the advantage of closely resembling the recessed light fixture hazard in terms of both type of exposure (low intensity, long term) and temperature. Furthermore, as was shown here it can be mathematically modeled. The results in the present study provide some calibration of the meaning of the test results in terms of other sizes and shapes of heat sources as well as other depths of insulation. This puts the results in a context which adds a perspective on the degree of hazard represented by a given ignition behavior in this test. 


\section{CONCLUSIONS}

Heat source/insulation configuration influences smolder ignition temperature more than any other parameter of this problem. The minimum heat source temperature necessary to cause ignition can be varied by at least $150^{\circ} \mathrm{C}$ as a result of variations in heat source geometry ranging from extended "concave" sources to sma11."convex". sources. The various potential ignition sources. in an attic space thus pose widely varying degrees of hazard. The impact of other parameters and even of smolder retardants is much less than this configuration effect. The reasonableness of this behavior has been established both by crude phenomenological models of heat flow/heat generation and by more accurate computer modeling. The model of this behavior implies that quite large reductions in heat generation rate below $300^{\circ} \mathrm{C}$ will be needed in order to eliminate the bulk of the smolder ignition hazard in cellulosic loose-fill insulations. The model also permits one to design a smolder test which provides a reasonably accurate measure of Ignition tendency in realistic usage circumstances.

\section{ACKNOWLEDGMENTS}

This work was sponsored by the Department of Energy under ORNL Sub Task IA-6113-4. The author would like to acknowledge frequent useful conversations with Dr. F. E. Rogers during the early stages of this work. 
6. NOMENCLATURE

E - effective activation energy

$\mathrm{E}_{1}=41,500 \mathrm{cal} / \mathrm{mol}$

$\mathrm{E}_{2}=39,300 \mathrm{cal} / \mathrm{mol}$

h - convective heat transfer coefficient

$\mathrm{h} \simeq 2.2-3.010^{-4} \mathrm{cal} / \mathrm{cm}^{2} \mathrm{sec}^{\circ} \mathrm{C}$; upward facing horizontal surface

$h \simeq 5.0 \cdot 10^{-5} \mathrm{cal} / \mathrm{cm}^{2} \sec ^{\circ} \mathrm{C}$; downward facing horizontal surface plus $8 \mathrm{~mm}$ transite board

$\ell$ - insulation layer thickness

$\ell_{2}$ - one-half of insulation layer thickness

$\ell_{R}-$ effective reaction layer thickness

$\ell_{S}-$ radius of cylindrical heat source

Q - heat release/g of material reacting

$\dot{q}-$ flux of heat/unit area

$\dot{q}^{\prime}$ - heat release/unit volume

r radial distance coordinate

R - universal gas constant

S - area

T - temperature

$\mathrm{T}_{\mathrm{A}}$ - ambient temperature

$T_{p}$ - temperature of heat source

$\mathrm{V}$ - volume

x - distance coordinate

y - distance coordinate 


$$
\begin{gathered}
\mathrm{z}-\text { composite pre-exponential factor } \\
\mathrm{z}_{1}=1.66 \cdot 10^{11} \mathrm{~g} / \mathrm{cm}^{3} \mathrm{sec} \\
\mathrm{z}_{2}=5.67 \cdot 10^{7} \mathrm{~g} / \mathrm{cm}^{3} \mathrm{sec}
\end{gathered}
$$

$\lambda$ - thermal conductivity of insulation

$$
\lambda \simeq 1.27 \cdot 10^{-4} \mathrm{cal} / \mathrm{cm} \mathrm{sec}{ }^{\circ} \mathrm{C} \text { (The, 1974) }
$$

58 
[1] Ames, W. (1965), Nonlinear Partlal Differential Equations in EngineerIng, Academic Press, New York, p. 378 .

[2] Beal1, F. and Eickner, H. (1970), Thermal Degradation of Wood Components: A Review of the Literature, USDA Forest Products Laboratory Research Paper FPL 130.

[3] Bowes, P. and Townshend, S. (1962), Ignition of Combustible Dusts on Hot Surfaces, Brit. J. App1. Phys. 13, p. 105.

[4] Britt, K: W. (1964), Handbook of Pulp and Paper Technology, Reinhold, New York, Chap. 2 and 9.

[5] Brookhaven National Laboratory (1978), An Assessment of Thermal Insulation Materials and Systems for Building Applications, Brookhaven Rept. BNL-50862.

[6] Carnahan, B., Luther, H. and Wilkes, J. (1969), Applied Numerical Methods, Wiley, New York, p. 508 .

[7] Carslaw, H. and Jaeger, J. (1959a), Heat Conduction in Solids, Oxford University Press, London, p. 126.

[8] Carslaw, H. and Jaeger, J. (1959b), op cit, p. 189.

[9] Day, M., Suprunchuk, T. and Wiles, D. (1979), A Technique for Evaluating the Smolder Resistance of Loose Fiber Fill Cellulose Insulation, J. Consumer Prod. Flamm., Vol. 6, p. 233.

[10] Eckert, E. and Drake, R. (1972), Analysis of Heat and Mass Transfer, p. 110.

[11] Gray, P. and Lee, P. (1967); Thermal Explosion Theory, in Oxidation and Combustion Reviews (C. F. Tipper, Ed.), Elsevier, New York.

[12] Gross, D. (1978), A Preliminary Study of the Fire Safety of Thermal Insulation for Use in Attics or Enclosed Spaces in Residential Housing, National Bureau of Standards NBSIR 78-1497, Washington, D.C.

[13] Issen, L. (1980), Fire Performance of Loose F111 Cellulosic Insulation in Residential Occupancies - A Progress Report, National Bureau of Standards NBSIR 80-2085, Washington, D.C.

[14] McDonald, H. (1979), Combustion Modeling in Two and Three Dimenstons--Some Numerical Considerations, Prog. Energy Combust. Sci., Vol, 5, p. 97-122.

[15] Merzhanov, A. and Averson, A. (1971), The Present State of the Thermal Ignition Theory; An Invited Review, Combustion and Flame, Vol. 16, pp. 89-124.

[16] Ohlemiller, T. and Rogers, F. (1980a), Cellulosic Insulation Material II. Effect of Additives on Some Smolder Characteristics, Combustion Sclence and Technology, in press.

[17] Ohlemiller, T. and Rogers, F. (1980b), Smoldering Combustion Hazards of Thermal Insulation Materials, final report on DOE Contract ORNL/76086, Princeton University, Princeton, N.J.

[18] Perry, J. (ed.) (1950), Chemical Engineers Handbook, Third Edition, McGraw-H111, New York.

[19] Rogers, F. and Ohlemiller, T. (1980), Cellulosic Insulation Material I. Overall Degradation Kinetics and Thermochemistry, Combustion Science and Technology, in press.

[20] Schaffer, E. (1979), On Smolder Initiation in Cellulosics Under Prolonged Low Level Heating, to be published in Fire Technology. 
[21] Shafizadeh, F. and Bradbury, A. (1979), Thermal Degradation of Cellulose in Nitrogen and Air at Low Temperature, J. App1. Poly. Sc1., Vol. 23, p. 1431-1442.

[22] Summerfield, M., Ohlemiller, T. and Sandusky, H. (1978), Thermophysical Mathematical Model of Steady-Draw Smoking and Predictions of Overall Cigarette Behavior, Combustion and Flame, Vol. 33, pp. 263-279.

[23] Thomas, P. and Bowes, P. (1961), Thermal Ignition in a Slab with One Face at a Constant High Temperature, Trans. Farad. Soc. 57 Part II, p. 2087.

[24] Tye, R. (19.74), Heat Transmission in Cellulosic Fiber Insulation Materials, J. of Testing and Evaluation, Vol. 2, No. 3, p. 176.

[25] Yarborough, D., Yoo, K. and Konen, P. (1979), Recessed Light Fixture Test Fac1lity, Oak Ridge Nationa1 Laboratory ORNL/SUB-7504/3.

[26] Zicherman, J. and Fisher, F. (1978), Fire Protection Problems Associated with Cellulose-Based Insulation Products, Soclety of Fire Prótection Engineerling Technology Report \#78-7. Boston. Mass.

[27] Lucca, D. (1981), "An Investigation of Co-Current and Counter-Current Smoldering Combustion in Particulated Fuel Beds" MSE Thesis, Dept. of Mechanical and Aerospace Engineering, Princeton Univeraity, Princeton, N:J. 
A

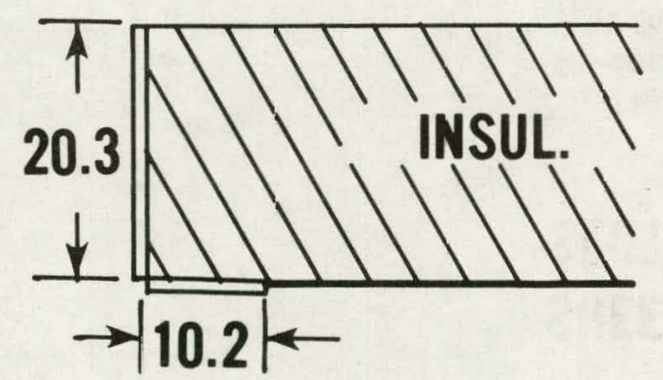

D

$\stackrel{9}{\mapsto}$
B

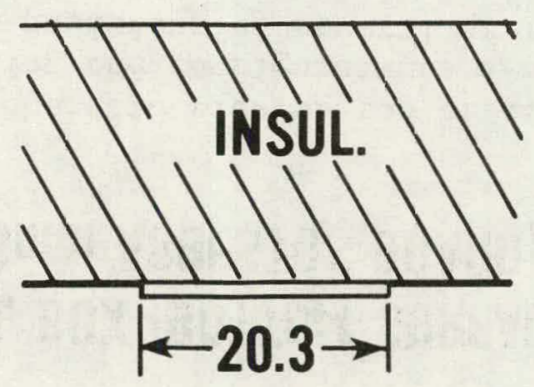

E

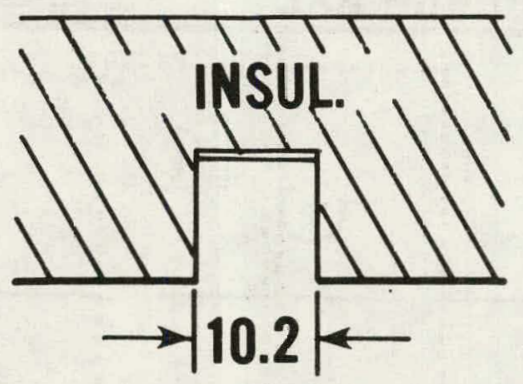

C

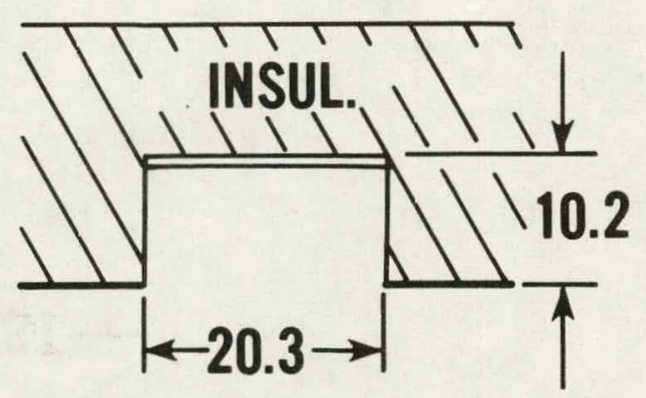

H

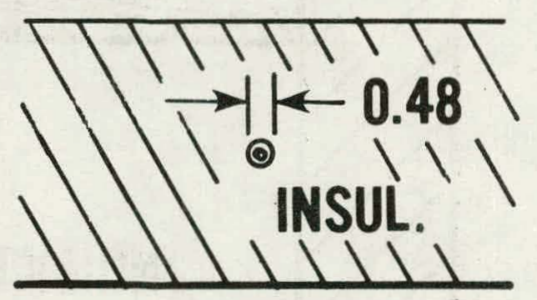

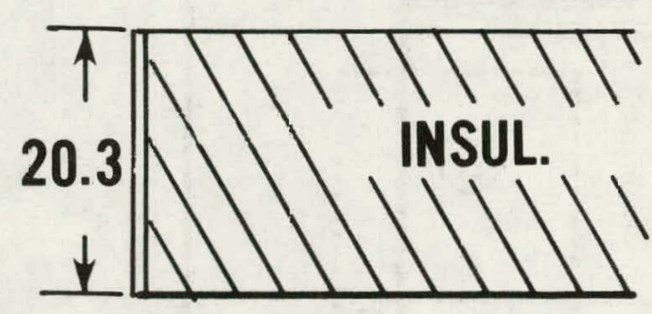

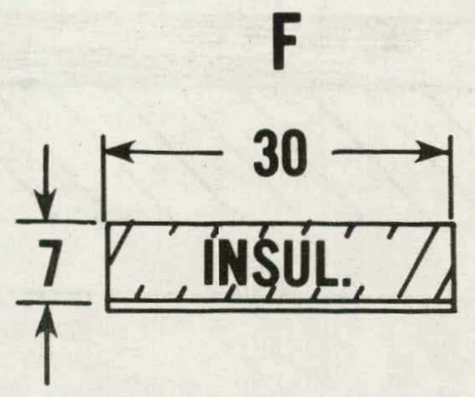

G

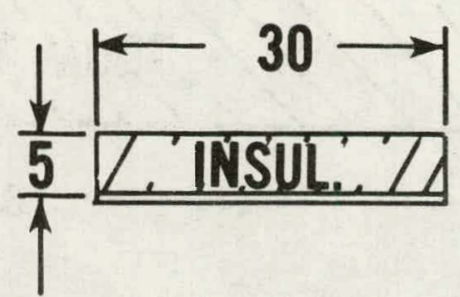

Figure 1. Schematic cross-sectional view of the eight configurations tested. The double-line border segment represents the fixed temperature heat source; elsewhere the insulation bed rests on $6 \mathrm{~mm}$ asbestos board. The dimensions shown are in centimeters and they apply to all similarly sized parts. Configurations $\mathrm{F}$ and $\mathrm{G}$ provide width to depth ratios that yield essentially 1-D heat flow at the sample center. 


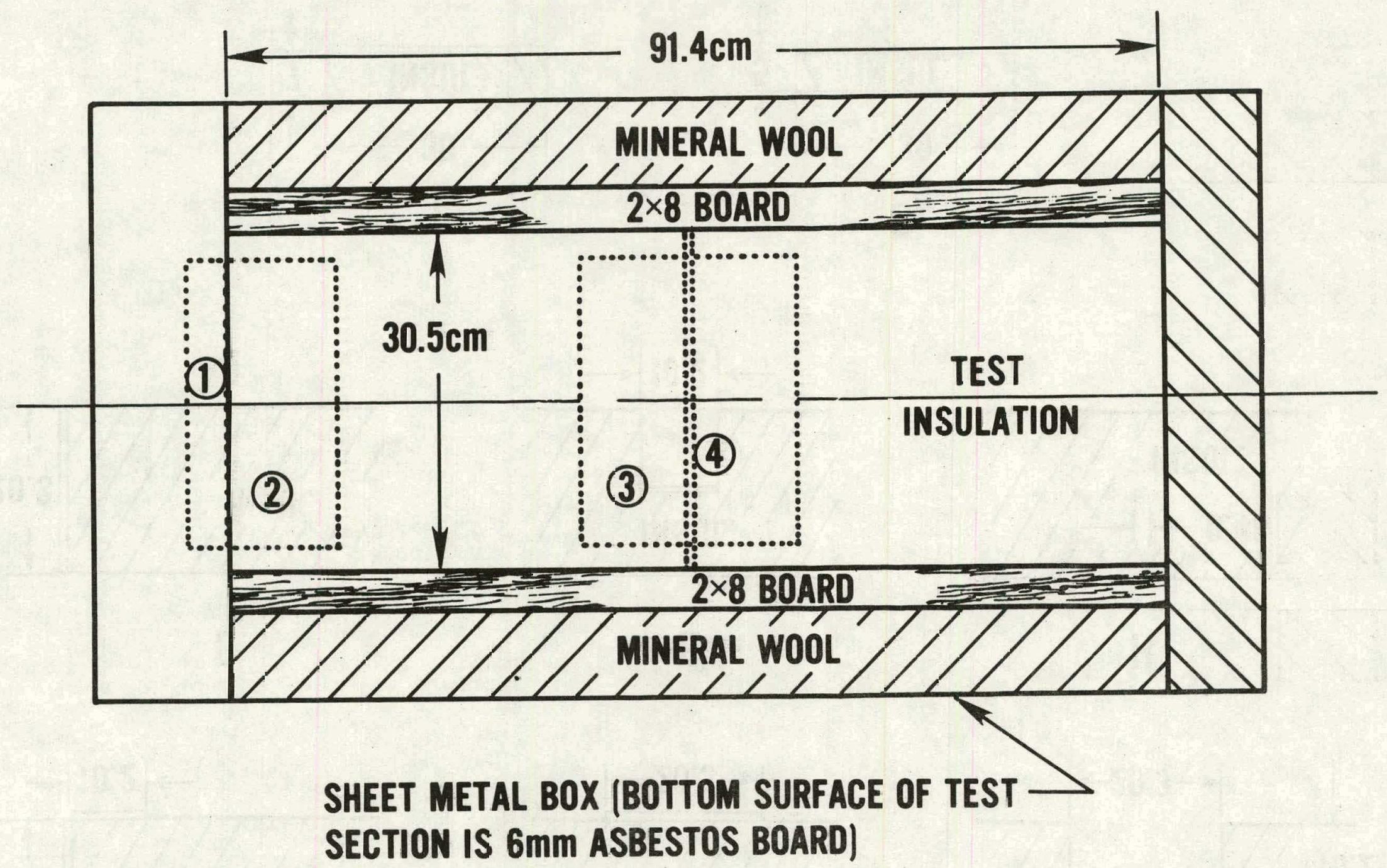

Figure 2. Schematic view of top of attic nock-up holding the configurations $A-H$ of Fig. 1. The positions of several of the sources are indicated: 1 equals $D ; 1$ plus 2 equals $A ; 3$ corresponds to $B$ or $C ; 4$ corresponds to $\mathrm{H}$. 


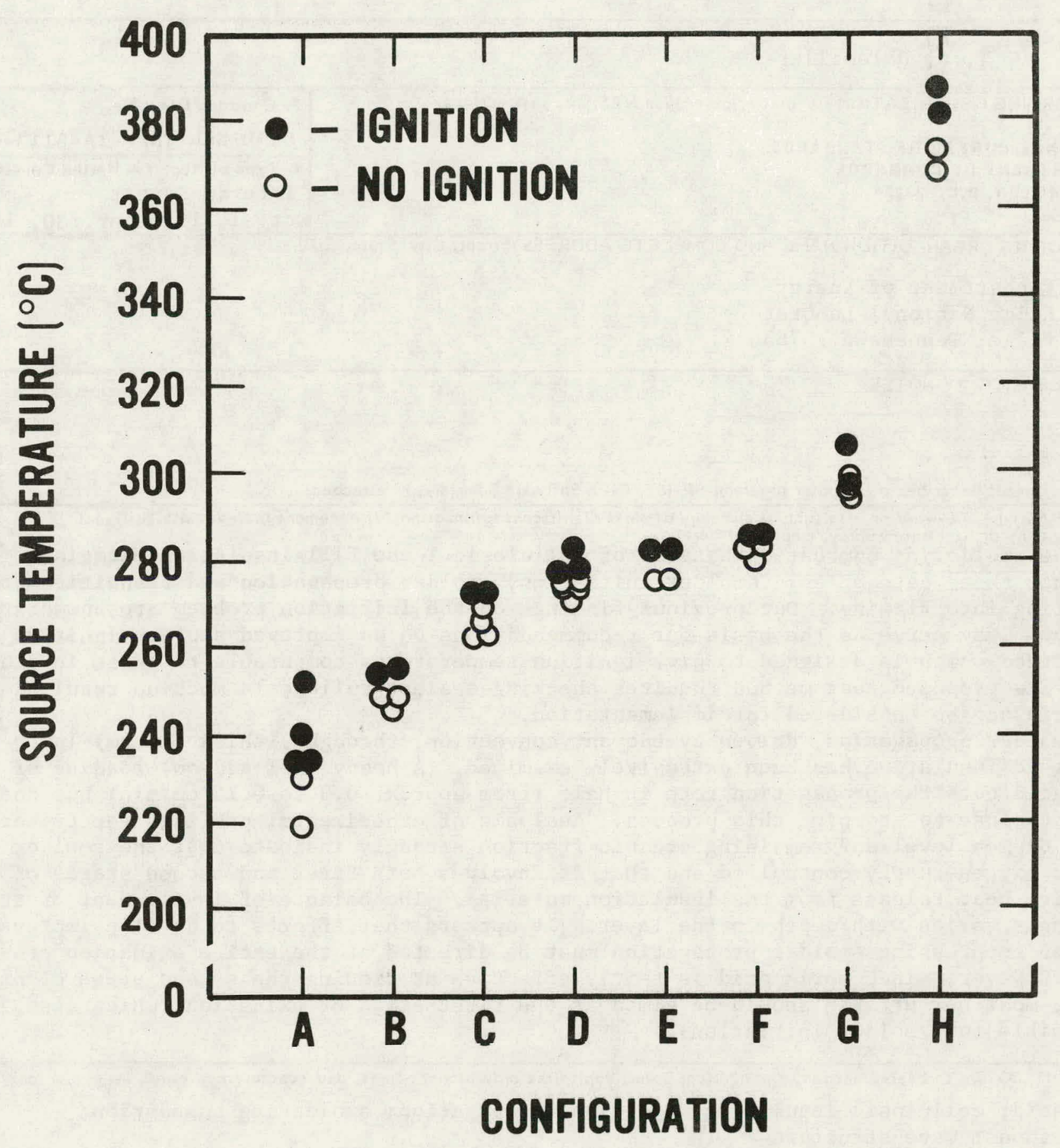

Figure 3. Results of ignition tests on the eight heat source configurations. $F$ and $G$ are the 1-D layers ( $7 \mathrm{~cm}$ and $5 \mathrm{~cm}$, respectively). 
NBS-114A (REV. 2-80)

U.S. DEPT. OF COMM.

BIBLIOGRAPHIC DATA

SHEET (See in structions)

1. PUBLICATION OR REPORT NO.

NBSIR $81-2350$

2. Performing Organ. Report No 3 . Publication Date

August 1981

4. TITLE AND SUBTITLE

Smoldering Combustion Hazards of Thermal Insulation Materials

5. AUTHOR(S)

T. J. Ohlemiller

6. PERFORMING ORGANIZATION (If joint or other than NBS, see instructions)

NATIONAL BUREAU OF STANDARDS

7. Contract/Grant No.

DEPARTMENT OF COMMERCE

WASHINGTON, D.C. 20234

ORNL Sub Task IA-611:3-4

9. SPONSORING ORGANIZATION NAME AND COMPLETE ADDRESS (Street。 City, State, ZIP)

8. Type of Report \& Period Covered

Interim Report

bct. 1, 1979-Apr. 30, 198

U.S. Department of Energy

Oak Ridge National Laboratory

Oak Ridge, Tennessee 37830

10. SUPPLEMENTARY NOTES

Document describes a computer program; SF-185, FIPS Software Summary, is attached.

11. ABSTRACT (A 200-word or less factual summary of most significant information. If document includes a significant bibliography or literature survey, mention it here)

The smoldering combustion hazards of cellulosic loose fill insulation materials

fall into three categories: smolder initiation, smolder propagation and transition from smoldering into flaming. Our previous findings on the initiation problem are summarized briefly. They serve as the basis for recommendations on an improved smolder ignition test method which is designed to give ignition temperatures comparable to those in practice. The proposed test method requires checking against full-scale mock-up results before it. can be considered for implementation.

Smolder propagation, driven by buoyant convection, through a thick (18 cm) 1 ayer of cellulosic insulation has been extensively examined. A heavy (25\% add-on) 1oading of boric acid cuts the propagation rate in half (from approx. $0.3 \mathrm{to} 0.15 \mathrm{~cm} / \mathrm{min}$ ) but does not come close to stopping this process. Analysis of experimental profiles for temperature, oxygen level and remaining organic fraction strongly indicate that the smolder wave is oxygen-supply controlled and that it involves both first and second stages of oxidative heat release from the insulation material. The balance of involvcment of the two stages varies with depth in the layer. It appears that efforts to develop improved means of suppressing smolder propagation must be directed at the entire oxidation process. However, since boric acid is fairly effective at slowing the second stage of oxidation, most new efforts should be aimed at the first stage of oxidation (which also is responsible for smolder initiation).

12. KEY WORDS (Six to twelve entries; alphabetical order; capitalize only proper names; and separate key words by semicolons) Boric acid; cellulosic insulation; ignition; propagation; smoldering combustion; tcst methods; wave structure

\section{AVAILABILITY}

[X] Unlimited

For Official Distribution. Do Not Release to NTIS

14. NO. OF PRINTED PAGES

Order From Superintendent of Documents, U.S. Government Printing Office, Washington, D.C. 20402.

65

X Order From National Technical Information Service (NTIS), Springfield, VA. 2216I

15. Price

$\$ 8.00$ 